\title{
Building Energy Renovation and Smart Integration of Renewables in a Social Housing Block Toward Nearly-Zero Energy Status
}

\author{
Damien Gatt $^{1 *}$, Cedric Caruana ${ }^{2}$ and Charles Yousif ${ }^{1}$ \\ ${ }^{1}$ Institute for Sustainable Energy, University of Malta, Marsaxlokk, Malta, ${ }^{2}$ Industrial Electrical Power Conversion, Faculty of \\ Engineering, University of Malta, Msida, Malta
}

OPEN ACCESS

Edited by:

Benedetto Nastasi, Delft University of Technology,

Netherlands

Reviewed by:

Graziano Salvalai,

Politecnico di Milano, Italy

Martin Thalfeldt,

Tallinn University of Technology,

Estonia

*Correspondence:

Damien Gatt

damien.gatt@um.edu.mt

Specialty section: This article was submitted to

Sustainable Energy

Systems and Policies,

a section of the journal

Frontiers in Energy Research

Received: 10 May 2020

Accepted: 26 August 2020

Published: 24 September 2020

Citation:

Gatt D, Caruana C and Yousif C (2020) Building Energy Renovation and Smart Integration of Renewables in a Social Housing Block Toward

Nearly-Zero Energy Status.

Front. Energy Res. 8:560892.

doi: 10.3389/fenrg.2020.560892
Like other islands, Malta experiences great challenges to secure its energy supply and independence. Deep renovation of buildings to nearly zero energy and addressing "smartreadiness" are widely believed to contribute to solving such challenges, while meeting the exigencies of the 2018 European Union energy performance of buildings directive (EPBD). Nearly zero energy buildings benchmarks for residential buildings in Malta have been defined using established EPBD cost-optimal methodologies, however these guidelines detailing a one-step and one benchmark definition approach neglects peak loads, building-grid interaction requirements and energy storage. To counteract these inadequacies, this research proposes an innovative multi-criteria approach adapted from ISO 52000-1:2017 standard, which supports the new EPBD requirements for optimizing comfort and addressing energy poverty. This is carried out by first optimizing adaptive comfort in "free-running mode," before switching to mechanical space heating and cooling. When implementing this approach on a case study of an existing 40-family social housing block undergoing deep renovation, it was found that the discomfort hours have been reduced drastically, while the peak demand for the remaining discomfort hours requiring mechanical heating and cooling has been halved. Despite such positive impact of passive measures, the research has quantitatively demonstrated that given Malta's temperate climate, such measures have lower impact on the energy rating of the building, when compared to that achieved with active and renewable energy (RE) measures. Thus, the proposed multi-tier benchmarking approach ensures that each energy efficiency measure is appropriately weighted on its own merits, rather than lumping all measures under a single benchmark indicator. With regards to smartness indicators for load matching and grid interaction, a detailed analysis using system advisor model software demonstrated that battery energy storage systems have the capacity to match the RE supply to the demand, although this approach is still far away from being cost-optimal. The research concluded that RE incentives should therefore move away from feed-in tariffs and subsidize direct energy use, storage, and load matching given their high costs. Furthermore, the cost-optimal analysis should also quantify the costs of thermal discomfort, energy poverty and grid mismatch, to ensure a holistic approach to deep renovation of buildings. 
Keywords: nearly zero energy buildings, smart building, energy renovation, social housing, energy storage, load matching, thermal comfort

\section{INTRODUCTION}

Following on the European Union (EU) Energy Performance (EP) of Buildings Recast Directive 2010/31/EU (EU, 2010), the EU has recently published amendments to it in (EU) 2018/844 (EU, 2018), which will apply until 2030. It is within this framework of mindset that this research paper revolves, with the hindsight on how deep renovation of buildings can implement the exigencies of this new directive, particularly within the special case of islands.

The (EU) 2018/844 (EU, 2018) has emphasized on the requirement that all Member States (MS) provide a plan for building renovation strategies. It has also set the path on how this should be devised, to ensure proper monitoring of progress and a common level of harmonization across the Union. This paper addresses some of the main requirements of the directive with regards to renovation of a social housing block case-study, as follows:

(1) Development of "long-term renovation strategies, aiming at decarbonizing the national building stocks by 2050." Following on the outcome of the Interreg-Europe project: "Promotion of near zero $\mathrm{CO}_{2}$ emission buildings due to energy use-ZeroCO" (Interreg Europe, 2016), a social housing renovation project will serve as a testbed and "best practice" example;

(2) "Mobilizing investment in renovation of buildings." Based on the outcome of this study, cost-optimal analysis would reveal the measures that require financial support for deep renovation of social housing blocks;

(3) "Smart readiness indicator (SRI)" rating of buildings and promotion of smart technologies for temperature and indoor air quality (IAQ) control. Health, well-being, and comfort of tenants is to be promoted and considered in building energy needs calculations. Smart control of building energy systems and battery storage for the on-site solar photovoltaic (PV) system in the case-study will be optimized in terms of load matching and grid interaction. Furthermore, achieving adaptive indoor comfort and IAQ for free running buildings will be prioritized, with air-conditioning systems applied only where required.

With regards to energy storage, it is worth noting that the EP of buildings directive (EPBD) addresses the need to introduce effective operation that takes into consideration "optimum generation, distribution, storage and use of energy," in such a way that the energy protocols used are interoperable in a smart manner. Such approach is critical for islands given that they are usually characterized by specific challenges in maintaining their energy independence and diversifying their energy sources (Malta EU Presidency, 2017). This has been recognized at EU level with the launching of the Clean Energy for EU Islands Initiative that offers support to all EU islands, in terms of exchange of best practices, capacity building and advisory services (Clean Energy for EU Islands Secretariat, 2018).

Taking the example of the island of Malta, one notes that these challenges manifest themselves in a clear manner, as follows:

(1) Energy independence challenges: Synonymous with all islands, Malta lacks indigenous resources of fossil fuels, as well as facilities to treat crude oil or gas. Thus, most of the required energy is imported in its final refined state, for immediate consumption, which negatively impacts energy independence, security of supply as well as cost;

(2) Limited diversification of energy sources: Malta is densely populated and has very limited free land mass for implementing large-scale projects. As a result, the potential of renewable energy (RE) systems such as solar and wind energy farms are limited in size, which negatively impacts the diversification of energy sources. In Malta, only $8 \%$ of the total final energy consumption was generated from RE in 2018 (NSO, 2019). Electrical cable interconnections with neighboring countries may add to diversification of energy sources for islands, but they come with high risks associated with cable damage caused by anchored ships. In Malta, the $200 \mathrm{MW}$ alternating current underwater interconnector to Sicily, Italy that was commissioned in 2017 has already undergone one major failure due to anchor damages in 2019 (Enemalta, 2020);

(3) Over-dependence on electricity commodity: Islands are highly dependent on electricity especially for supplying power to buildings and for desalination or treatment of fresh domestic water supply. The share of other fuel sources such as wood, oil and gas in buildings is usually very low, unless these sources are available locally. In Malta, over $90 \%$ of energy used in dwellings is electricity, with less than $10 \%$ coming from liquefied petroleum gas for cooking and partial space heating in winter (Said, 2012).

Energy security is recognized as the primary challenge for islands and this is quite often seen at par with climate change concerns for many of them (Mitra, 2009). RE is often seen as the primary solution, but one needs to emphasize the role that energy efficiency should play in this situation, as well as energy storage. In fact, one aspect of energy storage is the ability to sustain energy security at multi-micro levels, rather than seeing it as an overall island-wide solution. A case in point is the possibility of incorporating energy storage at building block level, which would reduce the effect of power surges and cuts. Battery storage use within communities is however still in its infancy. A few projects that have investigated the utilization of energy storage to offset power dependency on the grid include the Horizon 2020 project entitled: "Storage-Enabled Sustainable Energy for Buildings and Communities" (SENSIBLE, 2015), that aimed at achieving energy storage during low energy demand and using it during peak hours. However, such an 
approach would only be financially attractive if there is marked difference between off and on-peak electricity tariffs. In many islands, such tariffs do not exist.

Focusing on Malta, the National Energy Efficiency Action Plan [Office of the Prime Minister (Energy and Projects), 2017] considers energy storage as still too expensive for implementation in the near future, even though regulation does not preclude their use. On the other hand, the National RE Action Plan for Malta (EWA, 2017) and National Energy and Climate Plan for 2030 (EWA, 2019) acknowledges the benefit of energy storage to shift electric loads and reduce peak demands, as well as operating at nearly-zero energy levels. However, currently the only economically viable energy storage medium is solarheated domestic hot water (DHW) storage. The National Energy and Climate Plan acknowledges that battery storage will have to play a role in stabilizing the grid as more solar PV systems are added to the electricity network. Thus, a pilot financial support grant to subsidize the integration of battery storage with PV systems in the form of a grant will be introduced in 2020. This will target early takers of PV grants whose feed-in tariff contracts have expired.

Currently, nearly zero energy buildings (NZEB) benchmarks for residential buildings in Malta have only been defined in line with the 2012 EPBD cost-optimal guidelines. NZEB EP requirements that fully consider the impact of energy storage and load matching have not yet been defined. The aim of this research is to propose an approach adapted from ISO 52000-1: 2017 (ISO, 2017a) for defining NZEB benchmarks for a housing building block in island states that fully meet the requirements of the new EPBD, while prioritizing energy security and grid stability. This is achieved by considering impact of peak loads, and the incorporation of energy storage and load matching in the derived NZEB definitions. Furthermore, the approach specifically tackles energy poverty for the housing sector by optimizing adaptive comfort approach first, before applying mechanical space heating and cooling. Also, this paper addresses a niche area whereby electrical energy storage within a social housing building block will be analyzed in detail to evaluate its potential to provide better energy security, lower peak demand and a more balanced nearly-zero energy profile.

\section{BACKGROUND AND LITERATURE REVIEW}

Within the framework of the EPBD, several steps have been legislated on ZEBs and these will be discussed in the following sections.

\section{Buildings Energy Performance Legislation in Europe}

Over the past few years, the drive to promote deep renovation inching closer to achieving ZEBs or at least NZEB has been gaining momentum in the EU. This is one of the key actions that Europe needs to apply to combat climate change and achieve the goal of carbon-neutral society in 2050. The 2010 EPBD recast (EU, 2010) introduced the term "Nearly Zero Energy Performance Building" (NZEB) defined as a building that "has a very high energy performance with a low amount of energy required covered to a very significant extent by energy from renewable sources, including energy from renewable sources produced on-site or nearby" and requires all new EU buildings to be NZEB by the end of 2020.

The EPBD (EU, 2010) also requires that MS “draw up national plans for increasing the number of nearly zero energy buildings. These national plans may include targets differentiated according to the category of building ... reflecting their national, regional or local conditions, and including a numerical indicator of primary energy use expressed in $\mathrm{kWh} / \mathrm{m}^{2}$ per year."

The targets for NZEB should cater not only for new buildings but also for existing ones undergoing deep renovation given that "MS shall, furthermore, develop policies and take measures ... to stimulate the transformation of buildings that are refurbished into nearly zero-energy buildings" (EU, 2010). The importance of a cost-effective renovation approach to NZEB is further stressed in the $2018 \mathrm{EPBD}$ (EU, 2018), which implies that deep renovation is a staggering process that ultimately leads to the full decarbonization of the building stock by 2050 .

The NZEB definition provided in the EPBD leaves room for interpretation given that the terms "nearly," "a very high energy performance with a low amount of energy," "to a very significant extent by energy from renewable sources" and the meaning of "nearby" RE are not quantified. The EU therefore puts the onus on MS to determine these terms in their NZEB definition, according to various factors such as the life cycle cost optimal level of primary energy use, the local weather climate, RE sources available and the level of ambition.

\section{Quantifying Nearly Zero Energy Performance Indicators for Different Building Categories}

In addition to defining NZEB EP levels, MS are required to define cost-optimal EP levels for different categories of new buildings or buildings undergoing major renovation. The cost-optimal EP levels are found by using the comparative methodology framework established by the European Commission (Parliament, 2012), which requires applying different combinations of energy efficiency and RE measures to typical buildings termed "reference buildings" using the national calculation methodology (NCM). The cost-optimal EP corresponds to that $\mathrm{EP}$ of the corresponding package of measure(s) leading "to the lowest cost during the estimated economic lifecycle." The cost-optimal EP level(s) should get updated and calculated every 5 years given technological advancement, EP improvements and cost reductions.

Once the cost-optimal EP level for different categories are defined, the NZEB EP level should not be less ambitious than cost-optimal levels. REHVA (Kurnitski et al., 2012) defines NZEB as "technically and reasonably achievable national energy use of $>0 \mathrm{kWh} / \mathrm{m}^{2}$ per year but no more than a national limit value of primary energy, achieved with a combination of best practice energy efficiency measures and RE technologies, which may or may not be cost optimal."

While cost-optimal EP levels provide a maximum threshold for MS to define NZEB EP requirements, a clear relation and distinction between cost-optimal and NZEB EP levels has not 
been established at EU level despite recent guidance (European Commission, 2016) by the EU Commission.

\section{Establishing a Comprehensive Definition Framework for Buildings to Nearly Zero Energy}

Even when replacing "Nearly" ZEB with the more objective term "Zero Energy Building" or "Net Zero Energy Building" to depict an energy use of $0 \mathrm{kWh} / \mathrm{m}^{2}$, there are still many aspects and options to consider to establish a comprehensive and objective definition framework for ZEB as discussed in Torcellini et al. (2006), Marszal et al. (2011), and Sartori et al. (2012) and to guide energy efficient design that ensures effective policy making. A single definition for ZEB buildings does not exist, and the suitability of one definition over another depends on the specific context (Sartori et al., 2012).

One major contribution to define ZEB was by Torcellini et al. (2006) who defined ZEB as: "a building with greatly reduced energy needs through efficiency gains such that the balance of the energy needs can be supplied by renewable technologies." They (Torcellini et al., 2006) put forward four different ZEB definitions when energy is produced on site ("on-site ZEBs") as follows:

Site ZEB: "A site ZEB produces at least as much energy as it uses in a year, when accounted for at the site"

Source ZEB: "A source ZEB produces at least as much energy as it uses in a year, when accounted for at the source." In this approach a primary energy balance is considered instead of a site energy balance.

Emissions ZEB: "A net-zero emissions building produces at least as much emissions-free $R E$ as it uses from emissionsproducing energy sources."

Cost ZEB: "In a cost ZEB, the amount of money the utility pays the building owner for the energy the building exports to the grid is at least equal to the amount the owner pays the utility for the energy services and energy used over the year."

All the different definitions of ZEB are considered appropriate. The choice between them depends on "the project goals and the values of the design team and building owner" (Torcellini et al., 2006). The EU NZEB definition considers both the Source ZEB and the Cost ZEB by requiring MS to establish EP benchmarks based on a primary energy balance, while considering a costoptimal approach based on life-cycle costs (LCC) excluding embodied energy but including the cost of carbon. The EU NZEB buildings approach has in fact been termed by Attia (2018) as "Net Zero Energy Cost Optimal Buildings," requiring MS to be consistent in the way they link cost-optimality with NZEB to facilitate its convergence. The Source ZEB vs. the Site $Z E B$ allows one to equate the energy value of the fuel types used on site and to better model the impact of the national energy system. On the downside, when a Source ZEB is compared to Site $Z E B$, the source energy use and fuel switching can have a larger impact on ZEB than energy efficient technologies (Torcellini et al., 2006).

A distinction was also made by Torcellini et al. (2006) between "on-site ZEBs" and "off-site ZEBs." "Off-site ZEBs" are defined as "ZEBs that have a portion of the renewable generation supplied by off-site sources.". Furthermore, Marszal et al. (2010) provides a further breakdown of energy supply options according to their distance from the building. The five supply options starting from the shortest distance to the building are: "Generation on building footprint," "On-site generation from on-site renewables" with generation taking place on the building site, "On-site generation from off-site renewables" (example Biomass) requiring energy carriers to be transported, "Off-site generation" and "Off-site supply," which require green energy from the grid.

The International Energy Agency (IEA) (Laustsen, 2008) also defines a "stand-alone ZEB" or "Autonomous ZEB" to distinguish between "grid connected" and "off grid ZEBs" for which energy storage is required. Berardi (2018) explains that the current expectation for ZEB is to be connected to the grid, because an "Autonomous $Z E B$ " requires expensive storage systems and large energy generation systems to cover the peak energy demands and periods of low RE generation (Marszal et al., 2011; International Energy Agency, 2015b). On the other hand, grid-connected solutions dynamically exchange energy with the grid energy infrastructure enabling one to balance RE supply and demand over a longer period.

The recent approach in most ZEB definitions, including NZEB requirements was to neglect the building-grid interaction requirements and depict the grid infrastructure as an unlimited source of energy storage with zero losses (Marszal et al., 2011). The emerging approach as demonstrated in IEA SHC Task 40 (International Energy Agency, 2015a) for ZEB/NZEB is for RE systems to be designed to work in synergy with the grid and not to put additional stress on its functioning (Sartori et al., 2012). This grid-integration approach aims to maximize the use of local RE and load matching, while requiring the use of smart controls (Candanedo et al., 2015; Berardi, 2018).

In its new EPBD update (EU, 2018), the EU has also understood the importance of grid integration for buildings and introduced a voluntary SRI for buildings. Two principle aims of the SRI are to enable buildings to increase on-site or nearby RE production and self-consumption, as well as to stimulate energy-storage capacities in buildings (Bean et al., 2018).

Based on the above and on the various definitions for ZEB and NZEB including indoor environmental requirements, it becomes apparent that a comprehensive definition for ZEB/NZEB should cater for the unique context of each MS, taking into consideration and choosing between the various factors discussed in the following section. These are reviewed in Buildings Performance Institute Europe (BPIE) (2011), Marszal and Heiselberg (2012), Sartori et al. (2012), International Energy Agency (2015a), and D'Agostino (2015).

These factors include proper consideration of the:

(1) Weighting system including:

a. Metric or unit of the balance and normalization (primary energy for the EPBD in $\mathrm{kWh} / \mathrm{m}^{2}$ per year);

b. symmetric or asymmetric weighting of two-way energy carriers;

c. weighting factors for fuel including time-dependent accounting.

(2) Building system boundary including: 
a. The physical boundary (single buildings not a building cluster for the EPBD);

b. the type of energy use included in the balance (balance boundary);

c. boundary conditions (functionality, space, effectiveness, climate, and comfort).

(3) ZEB/NZEB balance including:

a. The balancing period (annual for the EPBD);

b. the types of energy balance between weighted supply and weighted demand;

c. energy efficiency requirements (minimum requirements for energy efficiency may be set);

d. the energy supply options (threshold for the minimum share of RE to cover building's energy demand may be set).

(4) Temporal energy match characteristics including:

a. Load matching;
b. grid interaction.

A comprehensive review of load matching indicators for ZEB/ NZEB is provided in (Candanedo et al., 2015). In addition, ISO 52000-1:2017 (ISO, 2017a) Annex G provides a list of load matching and grid interaction indicators as follows:

I) The Use matching fraction $\left(f_{\text {use }}\right)$, which relates the electric energy produced on-site and directly used to the total electric energy use;

II) The Production matching fraction $\left(f_{p r}\right)$, which relates the electric energy produced on-site and directly used to the total electric energy produced on-site;

III) The Reuse production matching fraction $\left(f_{\text {reuse }}\right)$, which relates between the electric energy produced on-site and not directly used, and the total electric energy produced on-site.

IV) Measurement and verification

Given the complexity of defining ZEB/NZEB buildings, the flexible NZEB definition approach in the 2010 EPBD recast (EU, 2010) resulted in diverging definitions for NZEB adopted by the different MS. D'Agostino (2015) compared the different NZEB definition for each MS in terms of energy uses included in the definitions, building system boundaries, building classification/ typology considerations, weighting systems and balancing periods. While a flexible approach allows MS to establish their own definition that has the potential of catering best for their specific requirements, it adds complexity in comparing NZEB benchmarks and makes it difficult to gauge the levels of ambition of MS in decarbonizing their building stock. The new set of EPB standards aim to promote a more harmonized approach for assessing the EP of buildings and thus provide a more transparent and consistent platform for EP calculations between MS.

Moreover, the NCM is generally based on an asset rating approach with fixed schedules and comfort set-points and using software simulation that is compliant with the EPBD requirements to study the EP of buildings. The resulting EP indicator in $\mathrm{kWh} / \mathrm{m}^{2}$ per year of the building is then compared against the established NZEB benchmark for the specific building category and type, to determine compliance or otherwise. The measurement and verification approach to ensure that a certified NZEB will operationally achieve NZEB in practice requires to be further developed in the EPBD. In this regard, countries like the United Kingdom adopted the "Operational Rating" certification (Department for Communities and Local Government, 2015) with the advantage of using a Display Energy Certificate based on actual energy consumption, thus giving more confidence to the current energy rating of the building.

One of the fundamental steps leading to benchmarking of building energy rating is the proper choice of building stock reference building $(\mathrm{RB})$. Through clustering of the building stock and appropriate statistical analysis of their EP rating, RBs can be created. By performing simulations that combine building envelope, building energy systems and RE, it is possible to ultimately determine the cost optimal and the nearly zeroenergy levels for each category. Defining the appropriate number of RBs and their corresponding NZEB benchmarks is essential to avoid easily attainable or unrealistic indicators. Another important aspect to consider is whether to define one NZEB benchmark indicator for each RB or multiple indicators. This concept will be expanded upon in the next sections after reviewing the $\mathrm{ZEB} / \mathrm{NZEB}$ design process.

\section{The Zero Energy Building/Buildings to Nearly Zero Energy Design Process}

Building design for achieving ZEB/NZEB status involves a holistic or integrated design approach that uses a three-step fundamental process known as the "Trias Energetica" (The MaTrID project, 2014; O'Brien et al., 2015). Similar approaches based on the same principles are found in Chesire and Grant (2007), Department for Communities and Local Government (2008), Grondzik et al. (2010), Ma et al. (2012), and Tymkow et al. (2013). The priority is to first optimize the passive building design to minimize the demand for space heating, cooling, lighting, and possibly mechanical ventilation. This is followed by using active building energy efficient systems to meet the demand for space heating and cooling, lighting, water heating and ventilation, and finally provide on-site RE generation to offset that demand and reduce the building's carbon footprint (Berardi, 2018). This approach giving priority to architecture, bioclimatic design and energy efficiency (Attia, 2018) is especially important in island states like Malta that are significantly dependent on imported energy and have limited RE.

\section{A Multi-Indicator Benchmark Approach to the Zero Energy Building/Buildings to Nearly Zero Energy Design Process}

Generally, an EU NZEB primary energy indicator is expressed in $\mathrm{kWh} / \mathrm{m}^{2}$ per year. The essence of robust NZEB definition and EP indicator benchmarks with unambiguous terminology and definitions are required to empower different building professionals including architects, project managers and engineers to abide by the indicators, through an integrated design approach based on the "Trias Energetica" principle. In addition, an optimal integration of different building energy systems, products and technologies using a smart control 
approach is to be ensured. The NZEB definition and resulting indicators should also make it easier for MS to meet the requirements of the updated $2018 \mathrm{EPBD}$ (EU, 2018) in terms of the recently introduced SRI, while combating social issues such as energy poverty. The latter is achieved by ensuring adequate IAQ, comfort, well-being, and health in EU buildings, which feature prominently in the new EPBD.

The current approach that has generally been adopted is to set one EP benchmark indicator to certify a building as NZEB. Bean et al. (2018) has emphasized the shortcomings of specifying only one NZEB indicator and explained a situation wherein a "better energy performance could be achieved by simply switching the energy supply of a building to RE." A typical scenario is when the building envelope's passive measures are not optimized to reduce energy demand or inefficient equipment are not replaced, but the NZEB indicator would still be met by compensating these inefficiencies with an increased share of RE. Such an approach of meeting NZEB requirements goes against the spirit of the new $\mathrm{EPBD}$ and violates the integrated "Trias Energetica" design principles, by undermining the benefits the building fabric has on the thermal, visual (daylighting) and acoustic comfort of occupants. Furthermore, both passive measures and energy efficient equipment have a substantial impact on energy security, while the use of RE and load matching capabilities enhance the building's potential to shave off peak loads.

Such a scenario that gives priority to RE to achieve NZEB status is especially of concern in island states such as Malta. Malta has a temperate Mediterranean climate where the difference between interior and exterior temperatures are small and where the electricity tariffs are relatively low. This often leads to scenarios [as demonstrated in studies including Gatt and Yousif (2016b) and (2016a)], where the introduction of solar PV leads to a much shorter return on investment than the application of thermal passive measures especially given that PV in Malta benefit from significant fiscal incentives, while other energy efficiency measures have proportionally lower grants.

The new EPB standard ISO 52000-1:2017, which MS are encouraged to abide by, stipulates that "the use of only one requirement, e.g. the numerical indicator of primary energy use, can be misleading." Thus, in contrast to a single indicator, a multiple indicator strategy is proposed in which "different requirements are combined to a coherent assessment of nearly Zero-Energy Building." To avoid this misleading interpretation of the EP of a building, ISO 52000-1:2017 (ISO, 2017a) standard proposes a multi-indicator NZEB framework. The proposed methodology combines the different requirements in a logical assessment of NZEB complimenting the integrated "Trias Energetica" design principles together with the social and SRI needs of the EPBD. The ISO standard explains that the "proposed assessment methodology goes step by step from the needs to the overall EP expressed in primary energy use."

For the building to have a qualified NZEB status, each of the NZEB "requirements" are to be met. The following are the requirements stipulated in the ISO standard:

(1) First requirement: "The building Fabric (Energy needs)" accounting for the building envelope quality in terms of both insulation and thermal inertia, bioclimatic design, building zoning and the need to guarantee adequate environmental indoor conditions;

(2) Second requirement: "The total primary energy use" reflecting the performance of the technical building systems including active space heat and cooling systems, DHW and artificial lighting. This is expressed as primary energy;

(3) Third requirement: "Non-renewable primary energy use without compensation between energy carriers" directly reflects the use of non-primary energy given that both the energy exported to the grid and the compensation between different energy carriers (example between gas and on-site PV production) are not accounted;

(4) Final NZEB rating: "Numerical indicator of non-renewable primary energy use with compensation" accounts for both the compensation between energy carriers and the effect of exported energy.

The integrated design approach is facilitated in this multipleindicator structure because each requirement directly impacts the other. For example, the quality of the building fabric will influence the sizing of the space heating and cooling equipment and their part-load efficiencies in the second stage. Other factors such as lighting control requirements to integrate daylighting also require to be bridged between the first and second requirements. The third requirement indicator puts the SRI indicator requirement into perspective and its compliance is dependent on the grid interaction and load matching capabilities of the building, which can be enhanced via storage and smart control requirements. This third requirement is however also highly dependent on the quality of the building fabric and the efficiency of the equipment to minimize peak loads and therefore facilitate load matching and storage size optimization.

An interesting aspect of the multiple-indicator NZEB benchmark is the ability for policy makers to establish benchmarks that optimize each requirement from a costoptimal perspective in line with the EPBD cost-optimal method. This enables the cost-optimal combination(s) of measures to be transferred from one requirement to another thus ensuring full consideration of the cost-optimal approach when establishing each indicator. For instance, for the first requirement, the combination(s) of passive measures resulting to be cost-optimal when analyzing energy need in compliance with EN 16798-1 (CEN, 2019) comfort requirements are transferred to evaluate the second requirement. This facilitates the cost-optimal process and reduces the number of iterations of energy efficiency and $\mathrm{RE}$ combinations that require to be evaluated, which is consistent with the EPBD cost-optimal methodology proposed by Hamdy et al. (2013). Alternatively, the multi-benchmark approach allows MS to establish benchmarks for each step that goes beyond cost-optimal to prioritize aspects including comfort and grid interaction to fully meet the 2018 EPBD objectives.

Furthermore, this multi-benchmarking approach has the potential of allowing MS and the EU to more easily diversify 
between cost optimal and NZEB EP requirements for the different building categories. This is possible by mandating different number of requirements to be met for cost-optimality and NZEB, depending on the RE potential of the building type under consideration. The first two requirements should however always be mandatory for both cost-optimality and NZEB.

\section{Further Buildings to Nearly Zero Energy Challenges}

While NZEB definitions and benchmark indicators apply for both new and existing buildings [termed "Nearly zero building energy refurbishment" (NZER) in (Torgal et al., 2014)], one should be aware of the challenges imposed on building renovation (Anita et al., 2016). The proposed benchmarks should therefore be realistic but sufficiently ambitious to achieve deep renovation (Boermans et al., 2012) that meets the EU's 2050 objectives of reducing greenhouse gas emissions by $88-91 \%$ in 2050 , compared to 1990 levels (European Commission, 2011).

Different barriers for renovation include financial constraints and uncertainties as detailed in Menassa and Ortiz-Vega (2013), CommONEnergy (2013), Anita et al. (2016), and Intelligent Energy Europe (2014). While considering such barriers, policy makers should also be aware of the non-energy benefits of building renovation when stipulating NZEB EP indicators. These include improved staff productivity, reduced maintenance cost, better comfort and national energy security, reduced exposure to energy price volatility, reduced greenhouse gas emissions and the creation of jobs (Ernst \& Young, 2010; Sweatman and Managan, 2010; BPIE, 2013).

One barrier in the EPBD is the lack of a clear definition of NZEB for building refurbishment, including what is meant by the term "building undergoing major renovation," which, like a new building, is also required to meet cost-optimal EP requirements. When a staged retrofit strategy is taken, the opportunity for these buildings to meet cost-optimal EP may be missed given the subjective renovation definition. To counteract this barrier, the new 2018 EPBD requires MS to consider specific measures for "identifying trigger points in the lifetime of a building that could be an opportunity for renovation" and to introduce "building renovation passports" as reviewed in Fabbri et al. (2016) and Sesana and Salvalai (2018) and which concept is being design and demonstrated in the Horizon 2020 iBroad (IBRoad project, 2017) and ALDREN (ALDREN Project, 2017; Sesana et al., 2020) projects.

Another barrier to NZEB in practice is the requirement by MS to implement an updated national NCM to account for the optimal comfort and SRI requirements in the new EPBD, including the ISO 52000-1:2017 (ISO, 2017a) multi-indicator benchmark approach to NZEB. Such a tool requires to comply with EPB standards, fully track peak loads to account for grid integration and load matching capabilities and consider the impact of smart controls requirements, as aligned with the M10 EPB building automation and control standards. Such energy performance certificate (EPC) tools require to be fully dynamic, and not be quasi-steady state based. Quasi steady-state methods for generating EPCs are currently in use in many countries including Cyprus and Malta. Furthermore, a fully integrated NZEB design requires such EPC tools to be harmonized within a Building Information Modeling framework, supporting designers to efficiently optimize building EP.

\section{METHOD}

This section proposes an approach to derive NZEB benchmarks for social housing stock buildings in line with ISO 52000-1:2017 (ISO, 2017a). The method is computationally efficient and fully meets the aims of the new EPBD in terms of optimizing comfort, combating energy poverty, while improving the RE load matching and grid integration capabilities to meet the SRI requirements, and increase energy independence and security of small island states.

\section{Proposed Multi-Buildings to Nearly Zero Energy Indicator Benchmark Methodology}

Figure 1 depicts the proposed method. Once an RB representing a specific housing building stock under study is determined, ${ }^{1}$ the $\mathrm{RB}$ energy model (BEM) is constructed. To establish NZEB benchmarks for an existing building, the BEM is calibrated to validate its inputs. For social housing buildings in Malta, which are predominantly operated in a "free running mode," buildings should as a minimum be calibrated with respect to hourly indoor zone temperatures for studying thermal comfort. Calibration ensures that the simulated indoor temperature results based on the combination of inputs chosen for construction, infiltration and window opening schedules in the model match the measured indoor temperatures. The BEM operation schedules should follow the NCM.

To derive the abovementioned first NZEB indicator "The building Fabric (Energy needs)" for the calibrated BEM, a combination of passive measures $\left(\mathrm{COM}_{\mathrm{P}} \mathrm{S}\right)$ that have potential to improve thermal comfort and reduce the energy needs for space heating and cooling are first identified. For the base (i.e. existing pre-renovation envelope) scenario and each $\mathrm{COM}_{\mathrm{P}}$ (or a sample of $\mathrm{COM}_{\mathrm{P}} \mathrm{S}$ ), the summer discomfort hours based on the EN 15251 (CEN, 2007) [superseded by EN 16798-1 (CEN, 2019)] adaptive thermal comfort model is quantified, using dynamic simulation tools and the BEM in "free-running mode." A similar parametric exercise is also carried out to determine the space heating and cooling energy needs of the base BEM and $\mathrm{COM}_{\mathrm{P}} \mathrm{S}$ in compliance with ISO 52000-1:2017 (ISO, 2017a) to meet defined winter and summer comfort set points that are independent of the efficiency of mechanical equipment. These set-points comply with EN 16798-1 (CEN, 2019) predicted mean vote comfort criteria.

From the BEM $\mathrm{COM}_{\mathrm{P}}$ inputs and the corresponding simulation outputs, a global sensitivity analysis (SA) approach is carried out to statistically identify the category of measures having the biggest impact on adaptive comfort, space heating and cooling energy needs. In addition to the SA, a cost analysis is required to specifically derive the "optimal" $\mathrm{COM}_{\mathrm{P}}$. While the EPBD requires optimization from a minimum LCC approach, the process adopted here first prioritizes the minimization of

${ }^{1}$ Methods to define RBs are reviewed in Gatt et al. (2020). 


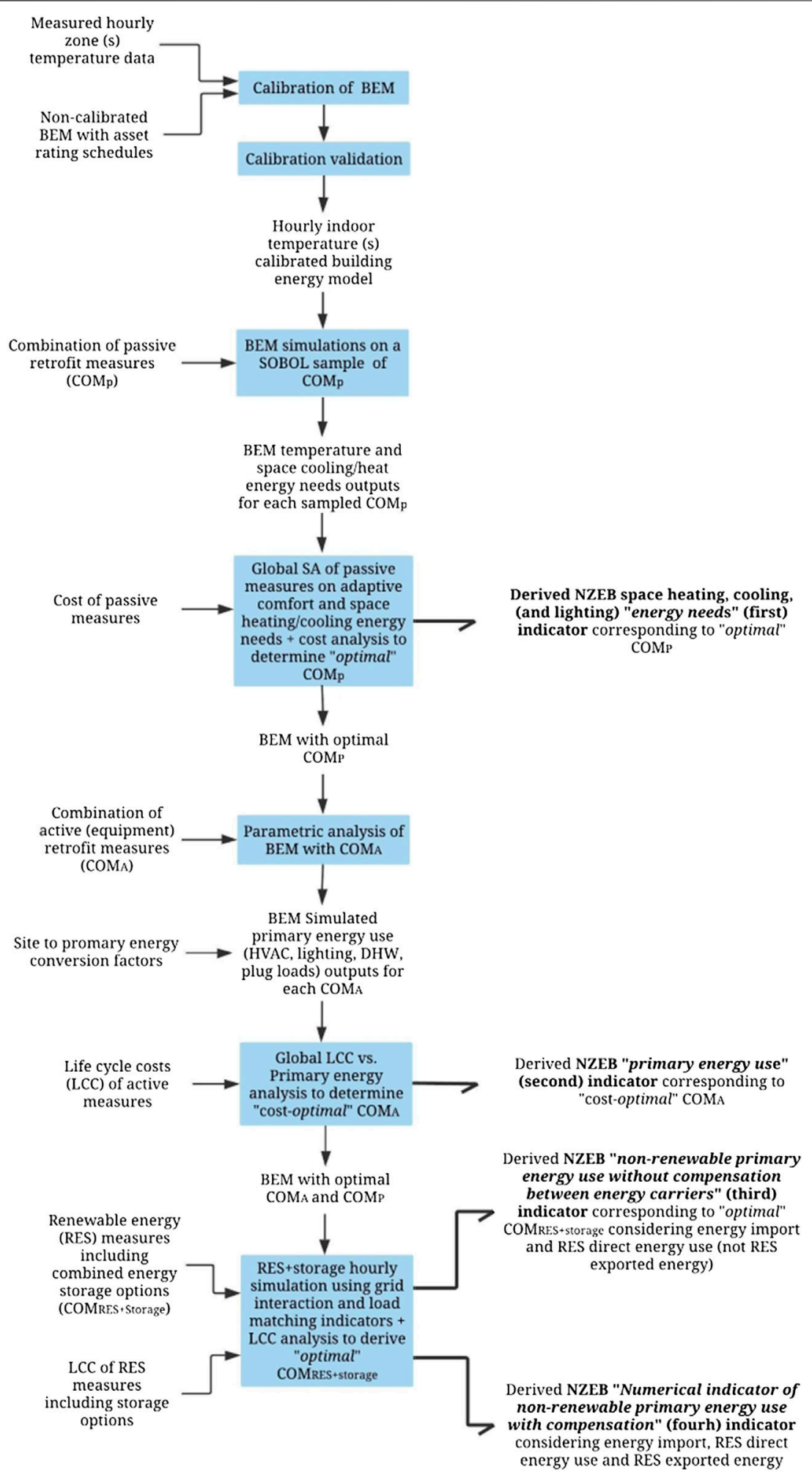

FIGURE 1 | Proposed multi-benchmark methodology approach to nearly zero energy buildings. 
discomfort hours and the decrease of heating/cooling energy needs, prior to reducing cost for the identified "optimal" $\mathrm{COM}_{\mathrm{P}}$. This will satisfy other EPBD requirements such as combating energy poverty and reducing peak heating/cooling energy needs. This optimization approach for the first NZEB requirement is being termed in this paper as "Pareto optimal minimal discomfort hours or heating/cooling energy needs at minimal cost." Once the "optimal" $\mathrm{COM}_{\mathrm{P}}$ is established, the first NZEB requirement is the simulated space heating and cooling energy needs of the BEM corresponding to the "optimal" $\mathrm{COM}_{\mathrm{P}}$.

The BEM with the applied "optimal" $\mathrm{COM}_{\mathrm{P}}$ inputs is then employed for the simulation runs to identify the second NZEB requirement of the building "the total primary energy use." Once combinations of active (equipment) measures are determined $\left(\mathrm{COM}_{\mathrm{A}} \mathrm{S}\right)$, the simulated energy use outputs of each $\mathrm{COM}_{\mathrm{A}}$ are converted to primary energy using the local site to primary energy conversion factors. Mechanical HVAC, lighting, DHW and plug loads in line with ISO 52000-1:2017 (ISO, 2017a) are accounted in the energy use. The global LCC for each simulated $\mathrm{COM}_{\mathrm{A}}$ is calculated in accordance with EN 15459-1 (CEN, 2017) and the "optimal" $\mathrm{COM}_{\mathrm{A}}$ corresponding to the lowest LCC is determined. "The total primary energy use" second NZEB requirement reflects the simulated primary energy use of the BEM with "optimal" $\mathrm{COM}_{\mathrm{A}}$ (and $\mathrm{COM}_{\mathrm{P}}$ ).

To generate the third NZEB requirement defined as "Nonrenewable primary energy use without compensation between energy carriers" the BEM with "optimal" $\mathrm{COM}_{\mathrm{A}}$ and $\mathrm{COM}_{\mathrm{P}}$ inputs is used for the simulation runs. RE with combined energy storage options $\left(\mathrm{COM}_{\mathrm{RE}+\text { storage }}\right)$ first require to be defined. Each $\mathrm{COM}_{\mathrm{RE}+\text { storage }}$ is dynamically simulated on an hourly basis, where the interaction between the BEM energy generation and energy demand is considered. The indicators that quantify the resulting RE grid matching and load matching as stipulated in ISO 52000-1:2017 for each simulation run are calculated. A LCC analysis for each $\mathrm{COM}_{\mathrm{RE}+\text { storage in }}$ compliance with EN 15459-1 (CEN, 2017) is also undertaken. It is proposed that to ensure RE sustainability and to prioritize energy security using energy storage for small island states, a macroeconomic LCC approach that does not consider any RE incentives is used for the analysis. The "optimal" $\mathrm{COM}_{\mathrm{RE}+\text { storage }}$ to derive the third NZEB requirement in which RE export to the grid is not considered, can be chosen to give the lowest LCC or preferably to meet SRI requirements on the "optimal" solution that aims to prioritize RE grid interaction and load matching prior to considering LCC.

The fourth NZEB requirement i.e. "Numerical indicator of non-renewable primary energy use with compensation" can then be calculated using the "optimal" $\mathrm{COM}_{\mathrm{RE}+\text { storage but }}$ also including exported energy as detailed in ISO 52000-1: 2017 (ISO, 2017a).

\section{CASE STUDY BUILDING}

The case-study chosen to demonstrate the methodology discussed in this chapter is a typical social housing block built

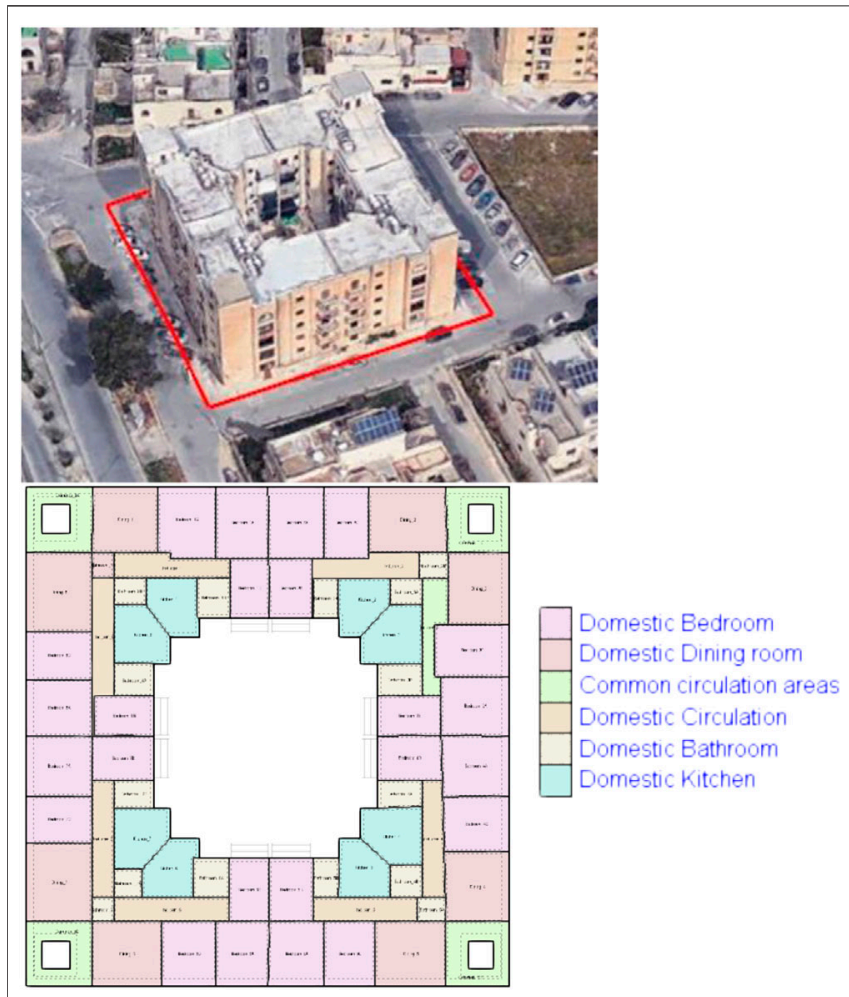

FIGURE 2 | The housing block under study (top image shows an aerial view of the block and the bottom image depicts a plan view of a typical floor in the housing block having eight apartments).

in the early 1990s in Malta. It is comprised of five floors each consisting of eight apartments. The housing block is thus made up of forty apartments in total. Figure 2 depicts the housing block under study.

\section{Description of the Housing Block Under Study}

The housing block has a square configuration with an internal central courtyard. The building has a site orientation of $\mathrm{N} 25^{\circ} \mathrm{E}$. Each floor in the block has an internal area of circa $1080 \mathrm{~m}^{2}$ while the perimeter of each external façade is approximately $37 \mathrm{~m}$. All apartments are made up of a similar layout as depicted in Figure 2. Each apartment is composed of a $25 \mathrm{~m}^{2}$ dining area accessed via entrance from a common circulation area, two large bedrooms each having an area of approximately $21 \mathrm{~m}^{2}$, a small bedroom with a floor area of $18 \mathrm{~m}^{2}$ having its external wall facing the courtyard, a kitchen with an area of $12 \mathrm{~m}^{2}$ and two bathrooms.

The uninsulated building's external double wall façade has a $\mathrm{U}$-value of $1.58 \mathrm{~W} \mathrm{~m}^{-2} \mathrm{~K}^{-1}$ and internal heat capacity (k-value ${ }^{2}$ ) of $149 \mathrm{~kJ} \mathrm{~m}^{-2} \mathrm{~K}^{-1}$. The single walls facing the courtyard have a
${ }^{2} \mathrm{k}$-Value is an abbreviation for Kappa value. It is a measure of the heat capacity per unit area of the "thermally active" part of the construction element $\left(\mathrm{kJ} / \mathrm{m}^{2} \mathrm{~K}\right)$ used in SAP and SBEM - the compliance tools for Part L of the Building Regulations in England. 
$\mathrm{U}$-value of $2.8 \mathrm{~W} \mathrm{~m}^{-2} \mathrm{~K}^{-1}$ and an internal heat capacity $(\mathrm{k})$ of $149 \mathrm{~kJ} \mathrm{~m}^{-2} \mathrm{~K}^{-1}$. The uninsulated roof has a U-value of $1.6 \mathrm{~W} \mathrm{~m}^{-2} \mathrm{~K}^{-1}$ and an internal heat capacity of $213 \mathrm{~kJ} \mathrm{~m}^{-2} \mathrm{~K}^{-1}$ while the uninsulated ground floor has a U-value of $1.97 \mathrm{~W} \mathrm{~m}^{-2} \mathrm{~K}^{-1}$ and an internal heat capacity of $176.85 \mathrm{~kJ} \mathrm{~m}^{-2} \mathrm{~K}^{-1}$. All construction thermal properties are calculated in compliance with ISO 6946 (ISO, 2017b). These thermal properties of the building were validated via BEM calibration as described in Calibration of Case Study Building Energy Model.

Furthermore, the entire building fenestration is composed of $6 \mathrm{~mm}$ single clear glazing with an uninsulated aluminum frame profile, having an overall $\mathrm{U}$-value of $6 \mathrm{~W} \mathrm{~m}^{-2} \mathrm{~K}^{-1}$. The dining area has an open-air balcony made of limestone with a horizontal projection of $1 \mathrm{~m}$. The balcony also incorporates limestone side fins being $1 \mathrm{~m}$ deep along its full edges. The balcony is accessed via a single glazed uninsulated aluminum door. In addition, one of the large bedrooms facing the external façade has a window opening, while the other large bedroom has a limestone balcony with a $1 \mathrm{~m}$ horizontal projection and limestone side fins only reaching half the height of the aluminum glazed door that provides access to the balcony. This same balcony configuration is also found for the small bedroom facing the courtyard.

An energy audit of the building was carried out and information was gathered through site visits and via interviews carried out to $85 \%$ of the residents. This audit enabled the characterization of the apartments both in terms of equipment and occupancy. The interviews also allowed the level of thermal comfort experienced by the occupants inside the different apartments to be assessed. From the occupants' feedback, a high level of discomfort exists inside the top floor apartments especially during summer. For the ground floor apartments, most occupants reported discomfort during winter, while thermal comfort was satisfactory during summer. For the middle floor apartment, $80 \%$ of occupants felt thermally comfortable throughout the whole year.

For equipment, all apartments are naturally ventilated and air changes inside the building are enabled only via infiltration and windows opening. In addition, $80 \%$ of the apartments operate the building in "free-running mode." The few apartments using splitunit reversible heat pumps for space heating/cooling only condition a maximum of two bedrooms primarily during the summer season and for a limited number of hours, while the rest of the apartment is not conditioned. For DHW, all the buildings make use of electric boilers with a storage capacity of between 50 and $80 \mathrm{~L}$, while most apartments still use compact fluorescent lighting for the major part of their lighting needs rather than light emitting diodes (LEDs).

\section{Calibration of Case Study Building Energy Model}

In addition to the walk-through energy audit and occupants' interviews, on-site measurements of dry-bulb temperature [using Onset HOBO UX100-003 (HOBO)] were taken for sample bedrooms and dining rooms in seventeen zones facing different orientations and situated at different floor levels. These measurements quantify the qualitative feedback from the occupants with regards to their level of comfort. All measured temperatures were taken in unconditioned zones. Temperature readings were logged in $10 \mathrm{~min}$ intervals for one whole year between April 2019 and March 2020, and then converted to average hourly readings.

In addition, the EP and thermal comfort of the building were also analyzed using EnergyPlus (Crawley et al., 2001) dynamic building energy simulation engine within DesignBuilder version 6 (DesignBuilder) graphical interface. For the BEM, the block geometry including its construction properties, DHW equipment and lighting efficiency were inputted. Infiltration was calculated using the "poor" crack template profile on the calculated natural ventilation tab option of DesignBuilder.

The BEM is first manually calibrated with respect to the metered hourly dry-bulb zone indoor temperatures. Calibration was performed separately for each of the 17 zones in the building were on-site temperature readings were available. For calibration, a tailor-made EnergyPlus Weather file was prepared using the external weather conditions data inputs during the same metering period as purchased from the Meteorological Office of the Malta International Airport.

For the calibration exercise, no air-conditioning was used, and the windows were set to half-open during the summer period for a typical number of hours as determined from the occupants' responses and closed in winter. Given that NZEB buildings in the $\mathrm{EPBD}$ are rated using an asset rating approach, the occupancy and equipment schedules inputs in the model were chosen as the DesignBuilder default schedules for residential buildings. DesignBuilder schedules reflect the UK NCM profile, which are akin to those employed in the NCM for Malta. Furthermore, the building's internal floors in the BEM were deemed to be adiabatic.

Once the required hourly simulations were performed, the calibration of the BEM was validated by comparing the metered hourly temperature data with the hourly temperature simulation outputs separately for each zone and for all months, using the ASHRAE guideline 14 (ANSI/ASHRAE, 2014) indicators of Normalized Mean Bias Error and coefficient of variance of the root mean square error $\mathrm{CV}$ (RMSE). For calibration, the roof and wall construction $U$-values were adjusted carefully within a specified uncertainty range until the calibration validation criteria were met. Once calibration was performed, the Normalized Mean Bias Error resulted to be less than $10 \%$ while the CV(RMSE) was less than $30 \%$ for all zones under study as per required validation criteria in ASHRAE guideline 14 . Such calibration enables policy makers to have confidence in the BEM, thus making it valid to be used for simulation of energy efficiency improvements and retrofitting measures.

\section{DERIVED BUILDINGS TO NEARLY ZERO ENERGY BENCHMARKS FOR THE CASE STUDY HOUSING BLOCK}

Following on the BEM calibration and the baseline inputs validation, the NZEB benchmarks based on the four requirements of the ISO 52000-1:2017 standard (ISO, 2017a) and the method described in Method section were derived. For this exercise, the 2010 EnergyPlus Weather file for Malta was used 
TABLE 1 | Passive measure options considered for the case study building

\begin{tabular}{|c|c|c|c|c|}
\hline Measure & Baseline & Option 1 & Option 2 & Option 3 \\
\hline External wall $\mathrm{U}$-value $\left(\mathrm{W} \mathrm{m}^{-2} \mathrm{~K}^{-1}\right)$ & 1.57 & 0.61 & 0.44 & - \\
\hline Courtyard wall $\mathrm{U}$-value $\left(\mathrm{W} \mathrm{m}^{-2} \mathrm{~K}^{-1}\right)$ & 2.8 & 0.73 & 0.5 & - \\
\hline Fenestration glazing $\mathrm{U}$-value $\left(\mathrm{W} \mathrm{m}^{-2} \mathrm{~K}^{-1}\right)$ & Single glazing clear (6 mm) (5.78) & $\begin{array}{l}\text { Double glazing }(6 \mathrm{~mm}) \text { each } \\
\text { pane + air gap }(3.09)\end{array}$ & - & - \\
\hline Fenestration frame $\mathrm{U}$-value $\left(\mathrm{W} \mathrm{m}^{-2} \mathrm{~K}^{-1}\right)$ & Aluminum (5.88) & PVC (3.48) & - & - \\
\hline Fenestration shading & No louvers & External louvers & - & - \\
\hline Roof U-value $\left(\mathrm{W} \mathrm{m}^{-2} \mathrm{~K}^{-1}\right)$ & 1.6 & 0.62 & 0.44 & 0.32 \\
\hline Ground floor U-value (W $\left.\mathrm{m}^{-2} \mathrm{~K}^{-1}\right)$ & 1.97 & 0.46 & - & - \\
\hline
\end{tabular}

as input for the BEM which is the same weather file as that for the NCM for Malta.

\section{First NZEB Requirement: "The Building Fabric (Energy Needs)"}

This section derived the first NZEB requirement indicator(s) for the building. A market research identified different passive retrofit measures as shown in Table $\mathbf{1}$.

Several advanced building envelope improvements have been discarded, either due to insufficient level of their market technology readiness or due to their high costs. These technologies include embedded wall phase-change materials, and thermochromic wall/roof paint.

As summarized in Table 1, the number of energy efficiency interventions for the building's envelope cover three measures for the external wall, three measures for the courtyard wall, two measures for fenestration glazing, two measures for shading, four measures for roof insulation, and two ground floor measures. Thus, if one carries a full parameterization exercise and study the impact on thermal comfort and $\mathrm{EP}$ for each possible $\mathrm{COM}_{\mathrm{P}}$ in the $\mathrm{BEM}$, one needs to consider a total of 576 simulation runs. This results in a highly computational expensive exercise, which is not practical to implement, given the large size of the BEM having multiple zones and complex shading elements.

Thus, to reduce the number of simulation runs, a SOBOL (Sobol', 1967) sample of a minimum of $80 \mathrm{COM}_{\mathrm{P}}$ S. i.e., $10 \times \mathrm{n}$ (Loeppky et al., 2009) $\mathrm{COM}_{\mathrm{P}} \mathrm{S}$, where $\mathrm{n}$ is the number of parameters, was chosen. The sample size and SOBOL algorithm were selected to cover the multi-dimensional space of parameters evenly. The sampled $\mathrm{COM}_{\mathrm{P}} \mathrm{S}$ were simulated in the BEM for both the summer and winter design (extreme weather) weeks to study summer adaptive discomfort hours, space heating and space cooling energy demand. ${ }^{3}$ Optimizing passive measures for those two weeks ensures best adaptive comfort conditions for the whole year, thus reducing the need for active heating and cooling and offsetting energy poverty.

Adaptive comfort was analyzed in BEM for all zones in each apartment, with the aim of maximizing comfort in each zone, while the cooling and heating need calculations were implemented only for the bedrooms and dining rooms,

${ }^{3}$ The heating and cooling set-points for the study were taken to be 21 and $25^{\circ} \mathrm{C}$, respectively. i.e., the areas of most occupancy, as it is not practical to mechanically space heat and cool a whole building in temperate climates like Malta, especially for a social housing block. The windows were scheduled to be $50 \%$ open in summer, when summer adaptive comfort was studied, while they were closed when analyzing space heating and cooling energy needs, to minimize losses.

The next step focused on determining the passive measures category that will statistically have the best benefit for comfort and energy needs. A global SA of the sampled inputs $\left(\mathrm{COM}_{\mathrm{P}} \mathrm{S}\right)$ and the resulting simulation outputs [EN 15251 (CEN, 2007) summer adaptive discomfort hours CAT I, CAT II and CAT III, ${ }^{4}$ heating and cooling energy needs] was applied. This SA was carried out separately for the entire top, middle and ground floor level zones. This multi-tier approach was necessary, because the occupants' feedback revealed varying levels of thermal comfort for the different floors. A whole building approach would have averaged out the peaks experienced in different floors, which did not reflect reality and therefore this approach was rejected.

The standardized regression coefficient (SRC) SA method as reviewed in Tian (2013), Nguyen and Reiter (2015), Menberg et al. (2016), and Yang et al. (2016) was applied using XLSTAT version 2020.1 (Addinsoft). As shown in Figure 3, each regression model provides a corrected $\mathrm{R}$ squared coefficient higher than 0.7 and analysis on the resulting SRCs is acceptable (Saltelli et al., 2004).

For the top floor level, Figure 3 shows that the most important measures positively impacting both summer adaptive comfort and cooling energy demand are roof insulation and fenestration external shading. Roof insulation is the most significant factor to reduce winter heating demand. To a lesser extent, external walls thermal insulation provide more benefits in winter, while double glazing has the lowest impact on comfort, possibly due to the limited glazed area in the building and the mild weather climate. On the other hand, the window frame type has no significant impact $(p>0.05)$.

For the middle floor, Figure 3 shows that fenestration external has the largest positive impact on adaptive comfort and space cooling energy needs, while wall insulation and double-glazing

${ }^{4}$ The EN 15251 (CEN, 2007) comfort categories represent different level of comfort expectations, with category I representing the highest level of expectation recommended for elderly and fragile people, level 2 represents an expectation level for new and renovated buildings while level 3 provides an acceptable to moderate level of expectation and may be used for existing buildings. 


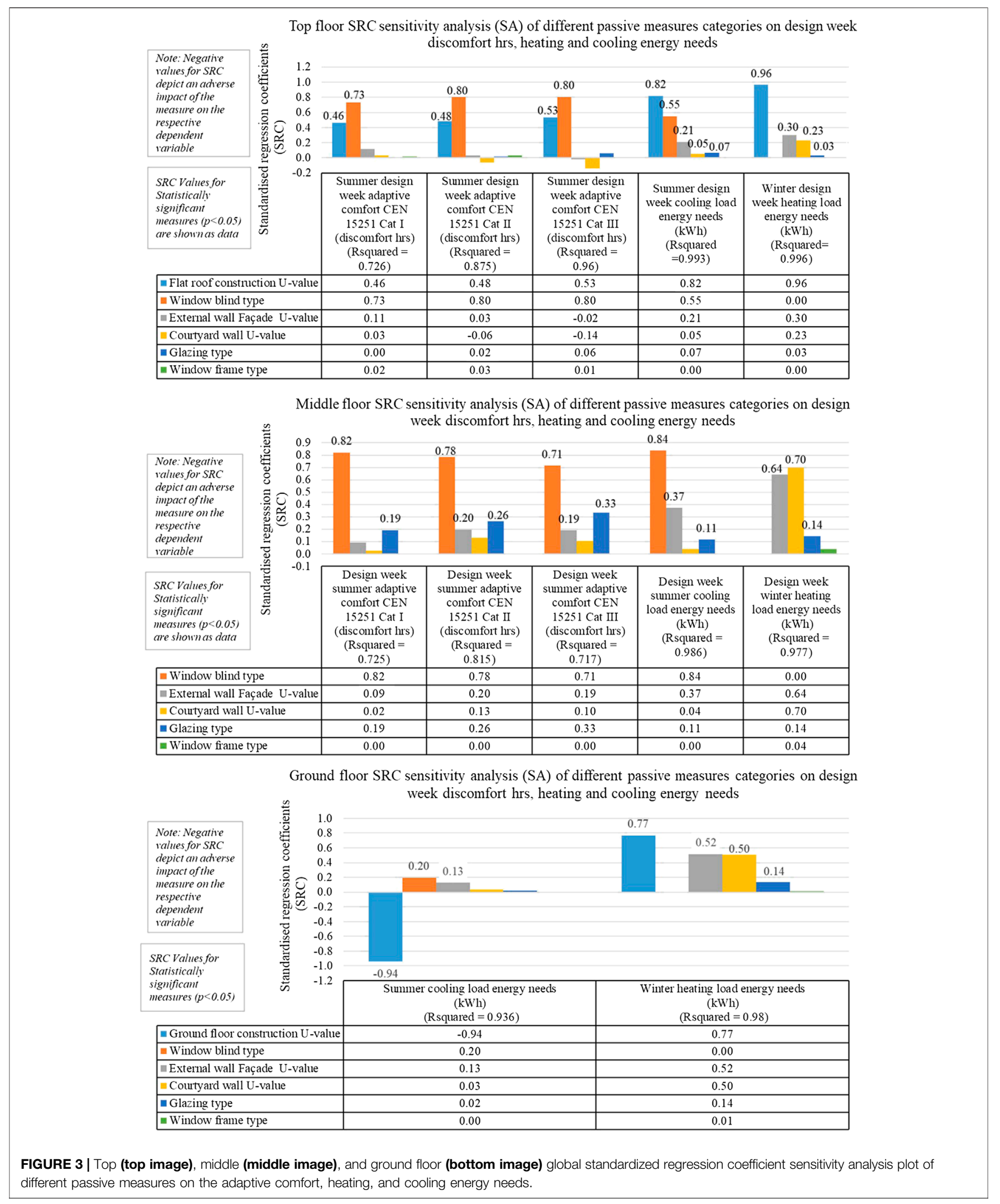


Top floor adaptive summer design week discomfort hours (hrs) vs. capital cost $(\epsilon)$

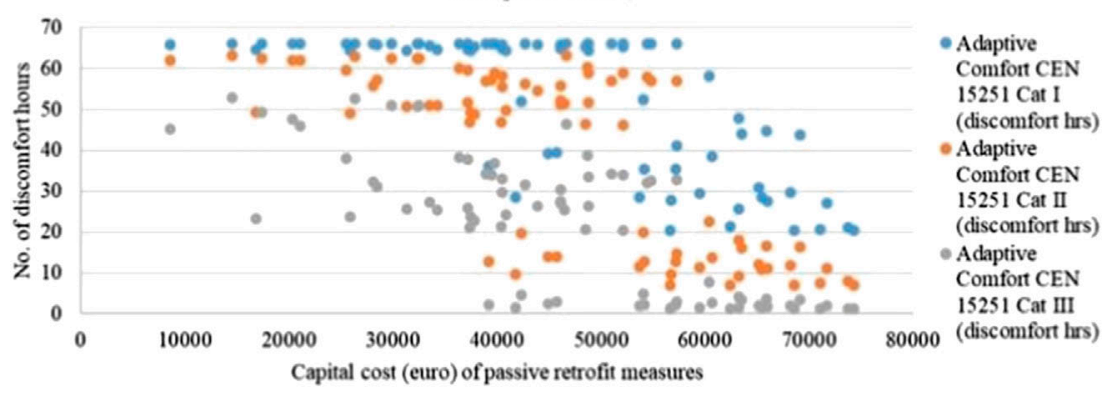

Middle floor adaptive summer design week discomfort hours (hrs) vs. capital cost $(\epsilon)$

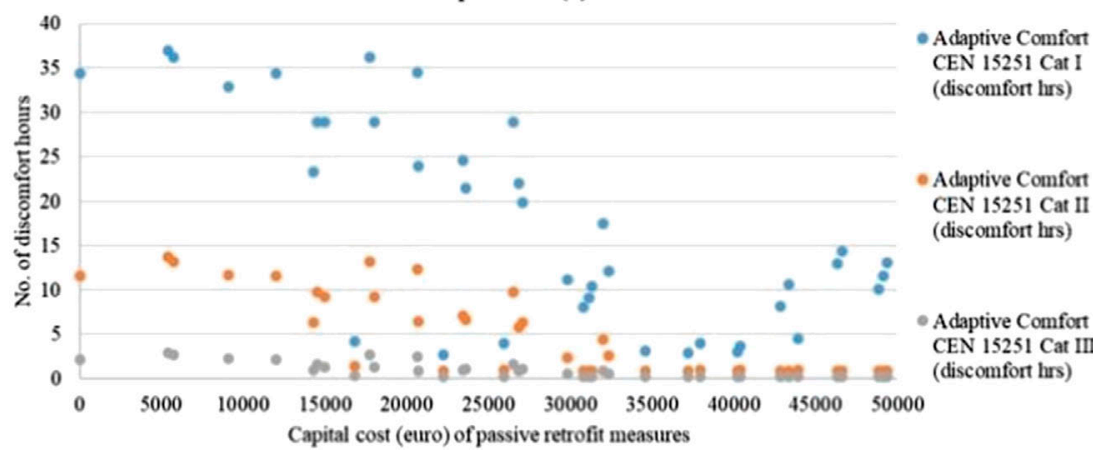

FIGURE 4 | Top floor (top image) and middle floor (bottom image) summer design week (adaptive comfort) discomfort hours vs. capital cost of passive retrofit measures.

measures improve comfort and reduce air-conditioning needs but to a lower extent. Within these later measures, insulating the courtyard walls had the best effect on lowering winter heating energy needs, followed by measures on the external façade walls, and to a much lesser extent double glazing. Once again, the window frame type has no significant impact $(p>0.05)$ on all considered outputs.

For Figure 3, SA was only performed on heating and cooling energy needs, given that summer adaptive comfort is fully satisfied based on the occupants feedback and confirmed by EnergyPlus simulations for all comfort categories in the base scenario (refer to Figure 4). The only measure with a positive significant impact on space cooling energy needs is fenestration external shading. Insulating the ground floor has a positive impact on the winter heating energy needs but increases the summer cooling energy needs significantly, because insulation blocks the ground slab from acting as a large heat sink. For winter, insulating the external façade, courtyard walls and to a lesser extent shifting to double glazing also reduce space heating needs significantly. These same insulation measures also have a positive impact on space cooling, but their impact did not result to be significant $(p>0.05)$. Similarly, the impact on all outputs when using insulated window frames instead of aluminum with no thermal break frames was found to be insignificant $(p>0.05)$.

The following step dealt with the cost analysis to specifically derive the "optimal" $\mathrm{COM}_{\mathrm{P}}$. The resulting adaptive discomfort hours, space heating and cooling energy needs for each sampled
$\mathrm{COM}_{\mathrm{P}}$ were plotted against their corresponding costs ${ }^{5}$ for all floors as shown in Figures 5 and 6. A cost-optimal approach to optimize summer comfort in the ground floor was not carried out given that for the baseline building, adaptive comfort was already satisfied. The aim of the optimization exercise for the first NZEB indicator as detailed in Method section is to find the $\mathrm{COM}_{\mathrm{P}}$ resulting in "Pareto optimal minimal discomfort hours or heating/ cooling energy needs at minimal cost" that prioritizes comfort and energy use reduction rather than the cost-optimal approach that optimizes the LCC.

The analysis from the plots yielded different pareto "optimal" $\mathrm{COM}_{\mathrm{P}} \mathrm{S}$ for summer discomfort hours, cooling, and heating energy needs for each floor. The results from these plots are summarized in Table 2 . To simultaneously satisfy the

\footnotetext{
${ }^{5}$ Only, the capital cost for implementing the passive measures was considered, because the maintenance cost was considered negligible. Also, energy costs for airconditioning were not considered because they are dependent on the equipment used and their technology. In this first step, one is only focusing on finding the optimal passive measures and not the optimal active systems. Passive measures capital costs: upgrade of roof $\mathrm{U}$-value to $0.62 \mathrm{~W} / \mathrm{m}^{2} \mathrm{~K}: 23.59 € / \mathrm{m}^{2}$, upgrade of roof $\mathrm{U}$-value to $0.44 \mathrm{~W} / \mathrm{m}^{2} \mathrm{~K}: 26.65 € / \mathrm{m}^{2}$, upgrade of roof $\mathrm{U}$-value to $0.32 \mathrm{~W} / \mathrm{m}^{2} \mathrm{~K}$ : $29.71 € / \mathrm{m}^{2}$, upgrade of external wall U-value to $0.61 \mathrm{~W} / \mathrm{m}^{2} \mathrm{~K}: 25 € / \mathrm{m}^{2}$, upgrade of external wall U-value to $0.44 \mathrm{~W} / \mathrm{m}^{2} \mathrm{~K}: 26.47 € / \mathrm{m}^{2}$, installation of external window blinds: $233.5 € / \mathrm{m}^{2}$, upgrade of courtyard wall U-value to $0.73 \mathrm{~W} / \mathrm{m}^{2} \mathrm{~K}: 25 € / \mathrm{m}^{2}$, upgrade of courtyard wall U-value to $0.5 \mathrm{~W} / \mathrm{m}^{2} \mathrm{~K}: 26.47 € / \mathrm{m}^{2}$, external window blinds: $233.5 € / \mathrm{m}^{2}$, double glazed aluminum fenestration: $208 € / \mathrm{m}^{2}$, double glazed PVC fenestration: $250 € / \mathrm{m}^{2}$, single glazed PVC fenestration: $167 € / \mathrm{m}^{2}$.
} 


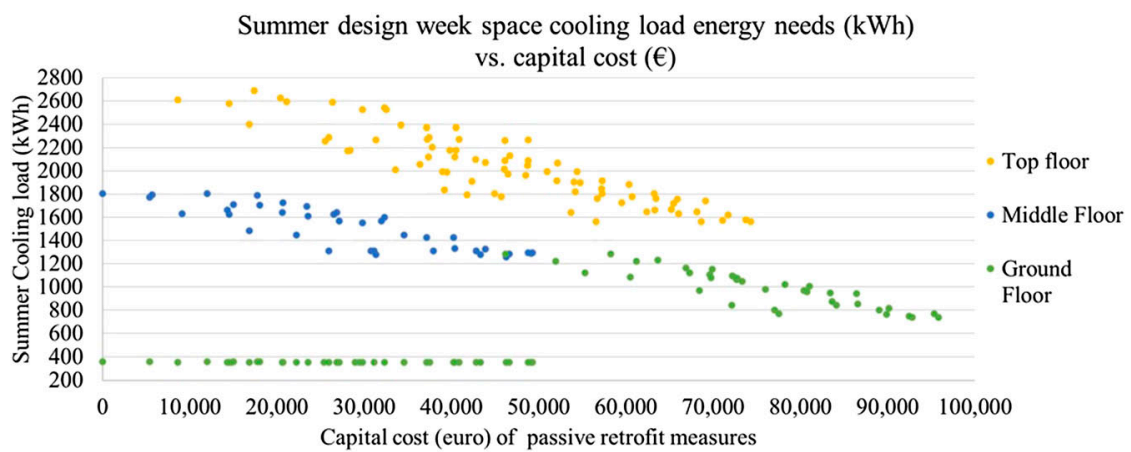

Winter design week space heating load energy needs $(\mathrm{kWh})$

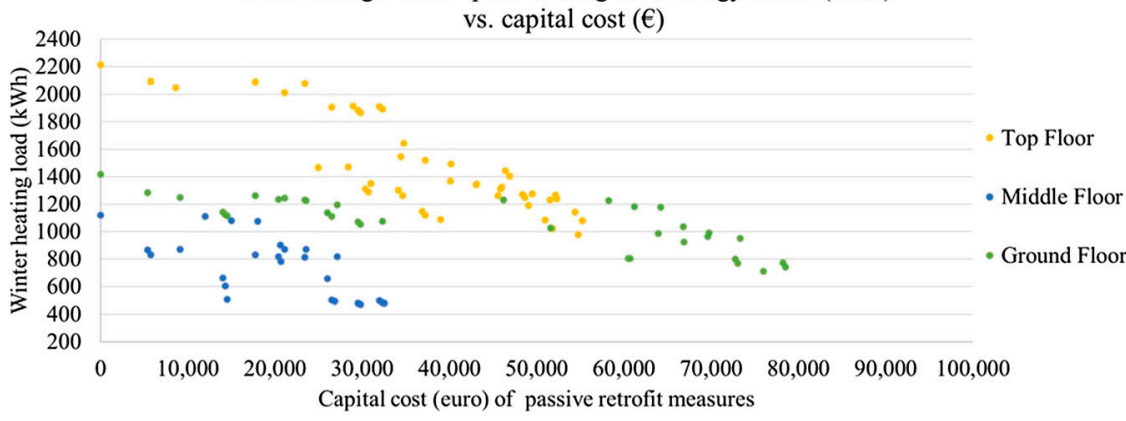

FIGURE 5 | Summer (top image) and winter (bottom image) design week cooling and heating load energy needs (kWh) vs. capital cost (€) of passive retrofit measures for each floor.

requirements for the discomfort hours, heating, and cooling energy needs for all floors, one requires a whole building $\mathrm{COM}_{\mathrm{P}}$ with a:

- Roof U-value of $0.32 \mathrm{~W} \mathrm{~m}^{-2} \mathrm{~K}^{-1}$;

- fenestration external shading via medium reflectivity solar blinds employed between 1st April to 30th September;

- external wall façade U-value of $0.44 \mathrm{~W} \mathrm{~m}^{-2} \mathrm{~K}^{-1}$;

- courtyard external wall U-value of $0.5 \mathrm{~W} \mathrm{~m}^{-2} \mathrm{~K}^{-1}$;

- fenestration single glazing;

- fenestration aluminum (non-thermal brake) frame;

- floor slab insulation required further analysis, as the SRC polarity was different for the cooling and heating energy needs in the SA SRCs.

Figure 6 shows that when the floor slab is insulated, the summer adaptive comfort is maintained within EN 15251 (CEN, 2007) limits and the thermal discomfort in winter is reduced. However, Figure 7 also shows than on an annual basis, adding floor slab insulation increases space cooling energy needs for the ground floor by $57 \%$, but when the space heating energy need is added, the combined energy needs for space cooling and heating are reduced by $29.5 \%$, when compared to the cost-optimal combination of passive measures excluding floor insulation. Therefore, the benefit is considerable and merits consideration. However, the implementation of this renovation measure in occupied buildings is difficult to implement, due to logistical reasons and added costs to replace all plumbing, electrical and drainage services that are usually passed along the floor slab. On the other hand, floor slab insulation should be favourably considered for new buildings.

Clearly, the study has shown that double glazing and insulation of fenestration frames have no significant influence on the thermal performance. However, these two measures will still be favourably considered, because they improve the indoor environmental performance in terms of noise reduction, and this is in line with the requirements of the updated EPBD (EU) $2018 / 844$.

Thus, from this analysis, the derived "optimal $\mathrm{COM}_{P}$ " that will be used to derive the first NZEB benchmark is composed of a roof $\mathrm{U}$-value of $0.32 \mathrm{~W} \mathrm{~m}^{-2} \mathrm{~K}^{-1}$, external solar blinds employed during the period of 1st April to 30th September, external wall façade $\mathrm{U}$-value of $0.44 \mathrm{~W} \mathrm{~m}^{-2} \mathrm{~K}^{-1}$, fenestration with double glazing and PVC frame having combined $\mathrm{U}$-value of $3.7 \mathrm{~W} \mathrm{~m}^{-2} \mathrm{~K}^{-1}$.

Figure 6 provides a time-series comparison of improvement in adaptive comfort by applying "optimal $C_{P} M_{P}$ " vs. the base scenario for all floors during the summer and winter design weeks. The EN 15251 upper and lower comfort limits are also shown.

Figure 7 depicts the reduction in heating and cooling energy needs between the base and "optimal $\mathrm{COM}_{P}$ " scenario for the top, middle and ground floors.

Given the variability in the resulting space heating and cooling needs, one should define space cooling and heating energy needs indicators corresponding to the optimal $\mathrm{COM}_{\mathrm{P}}$ for apartments found in different floors separately. This is 


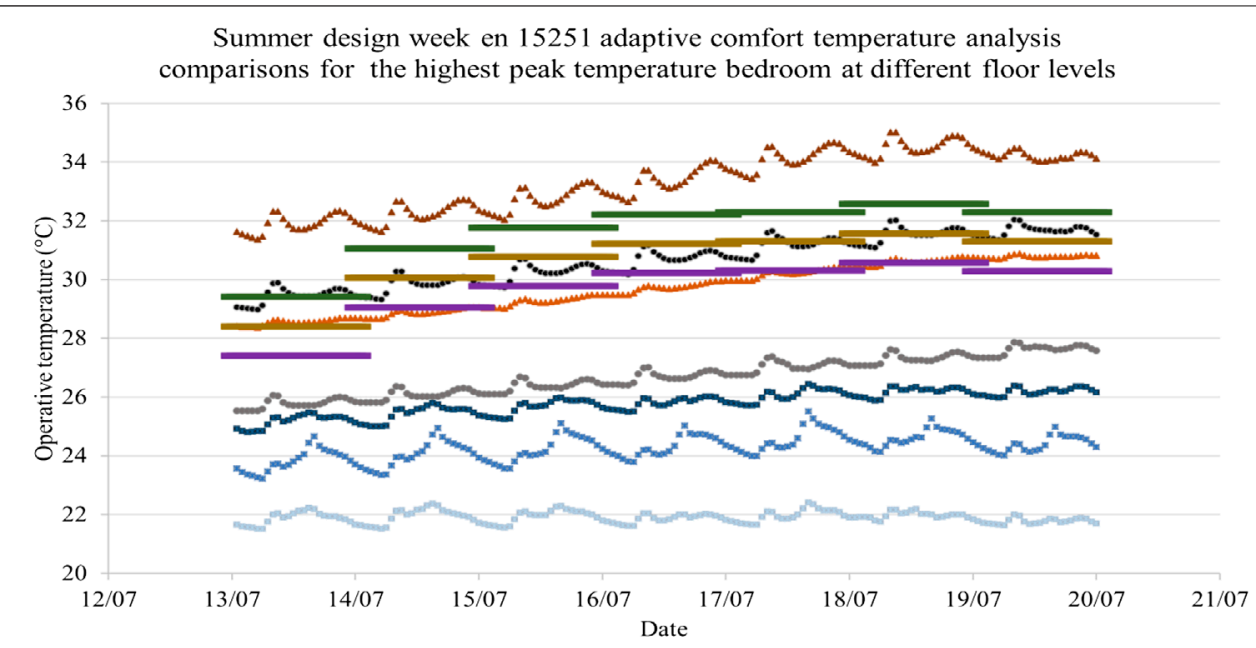

winter design week en 15251 adaptive comfort temperature analysis comparisons for the lowest peak temperature bedroom at different floor levels

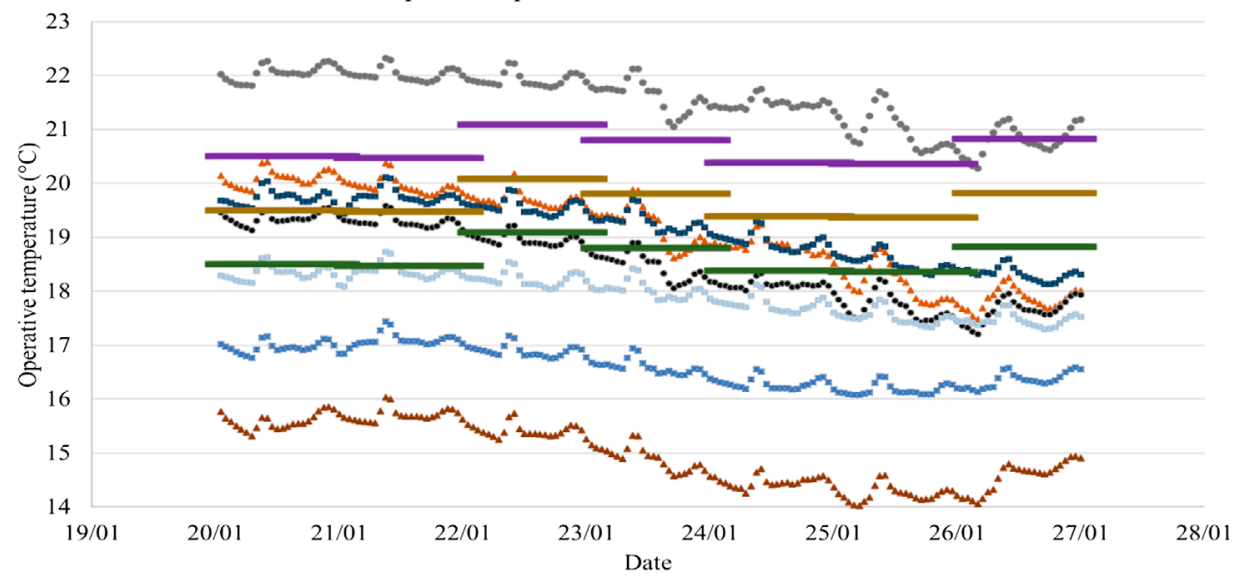

$\begin{array}{llll}\triangle \text { Top flr base } & \text { - Middle flr base } & \text { "Ground flr base } & \text { - CEN 15251 CAT I limit } \\ \text { A Top flr opt passive } & \text { - Middle flr opt passive } & \text { "Ground flr opt passive excl. floor ins } & \text { - CEN 1525 I CAT II limit } \\ & & \text { "Ground flr opt passive incl. floor ins } & \text { - CEN 15251 CAT III limit }\end{array}$

FIGURE 6 | Visual comparison of improvement in adaptive comfort using "optimal COMP" vs. the base scenario for each floor during the summer (top image) and the winter design week (bottom image).

carried out by normalizing the annual space cooling and heating energy needs for each floor level shown in Figure 7 by the combined area of apartments $\left(837 \mathrm{~m}^{2}\right)$ in each floor, excluding common areas. The indicators for the first NZEB requirements are depicted in Table 3 both for apartments at each floor level and for the whole building.

\section{Second NZEB Requirement: "The Total Primary Energy Use"}

When deriving the second requirement, the energy uses considered for the building are space heating and cooling, DHW, lighting and plug loads. The energy use schedules reflect the UK NCM. For the base equipment scenario for the second NZEB requirement, the building is modeled with the optimal $\mathrm{COM}_{\mathrm{P}}$ measures derived from the previous section,
LED lighting with power density $2.5 \mathrm{~W} \mathrm{~m}^{-2} \times 100 \mathrm{lux}^{-1}$ given that LEDs are currently installed by default in all buildings, and dedicated electric boilers for DHW equipment with SCOP $=0.75$, the technology currently used in the building.

Furthermore, despite the application of "optimal $\operatorname{COM}_{P}$," mechanical space heating and cooling equipment were still introduced in the BEM for the bedrooms and dining areas to ensure comfort is always met via reversible split unit heat pumps with a SEER of 5.6 and an SCOP of 4 complying with the A+ category in accordance with Commission Regulation (EU) No 206/2012 (European Commission, 2012). The only fuel source for the building is electricity with a site to primary energy conversion factor taken to be 2.5 as per default coefficients [Directive 2012/ 27/EU (European Parliament, 2012a)]. Table 4 row 1 depicts an energy use consumption breakdown for the base equipment scenario. 
TABLE 2 | Passive measures (COMPS) corresponding to the pareto optimal discomfort hours, cooling and heating energy needs at minimal cost for the top, middle and ground floors.

Floor

Variable under study
Pareto optimal minimal discomfort hours/energy needs

at minimal cost

(€) (1)
Corresponding values of variable under study

Top floor

Summer design week adaptive comfort CEN 15251 Cat I (discomfort hours)

Summer design week adaptive comfort CEN 15251 Cat II (discomfort hours)

Summer design week adaptive comfort CEN 15251 Cat III (discomfort hours)

Summer design week cooling energy needs (kWh)

Winter design week heating energy needs ( $\mathrm{kWh}$ )

Middle floor Summer design week adaptive comfort CEN 15251 Cat I (discomfort hours)

Summer design week adaptive comfort CEN 15251 Cat II (discomfort hours)

Summer design week adaptive comfort CEN 15251 Cat III (discomfort hours)

Summer design week cooling energy needs (kWh)

Winter design week heating energy needs ( $k W h$ )

Ground floor Summer design week adaptive comfort CEN 15251 Cat I (discomfort hours)

Summer design week adaptive comfort CEN 15251 Cat II (discomfort hours)

Summer design week adaptive comfort CEN 15251 Cat III (discomfort hours)

Summer design week cooling energy needs (kWh) Winter design week heating energy needs (kWh)

41,768

41,768

41,768

41,768

30,356

16,812

16,812

Adaptive comfort range satisfied for all combination of measures $\left(\mathrm{COM}_{\mathrm{P}} \mathrm{S}\right)$

$25,917 \quad 0.44,2.8$, yes-blinds, single glazing, Al frame

Adaptive comfort range satisfied for all combination of measures (COMPS)

Adaptive comfort range satisfied for all combination of measures (COMPS)

Adaptive comfort range satisfied for all combination of measures (COMPS)

60,517

$362^{\circ} \mathrm{kWh}$

$807^{\circ} \mathrm{kWh}$ $0.44,0.73$, none-blinds, single glazing, Al frame

\section{Measure corresponding to \\ pareto optimal minimal discomfort hours/energy needs \\ at minimal cost \\ $U$-value (flat roof \\ for top floor, \\ ground floor for \\ ground floor), external \\ wall, courtyard waln \\ blinds (yes or \\ fenestration glazing,}

0.32, 0.44, 0.5, yes-blinds, single glazing, Al frame

$0.32,1.58,2.8$, yes-blinds, single glazing, Al frame

$0.32,1.58,2.8$, yes-blinds, single glazing, Al frame

$0.32,0.44,0.5$, yes-blinds, single glazing, Al frame $0.32,1.58,0.73$, none-blinds, single glazing, Al frame $1.58,2.8$, yes-blinds, single glazing, Al frame

1.58, 2.8, yes-blinds, single glazing, Al frame

Wher design week heatng enegy needs (kthi)


Annual space heating and cooling energy needs (kWh) for different floors and passive measure scenarios

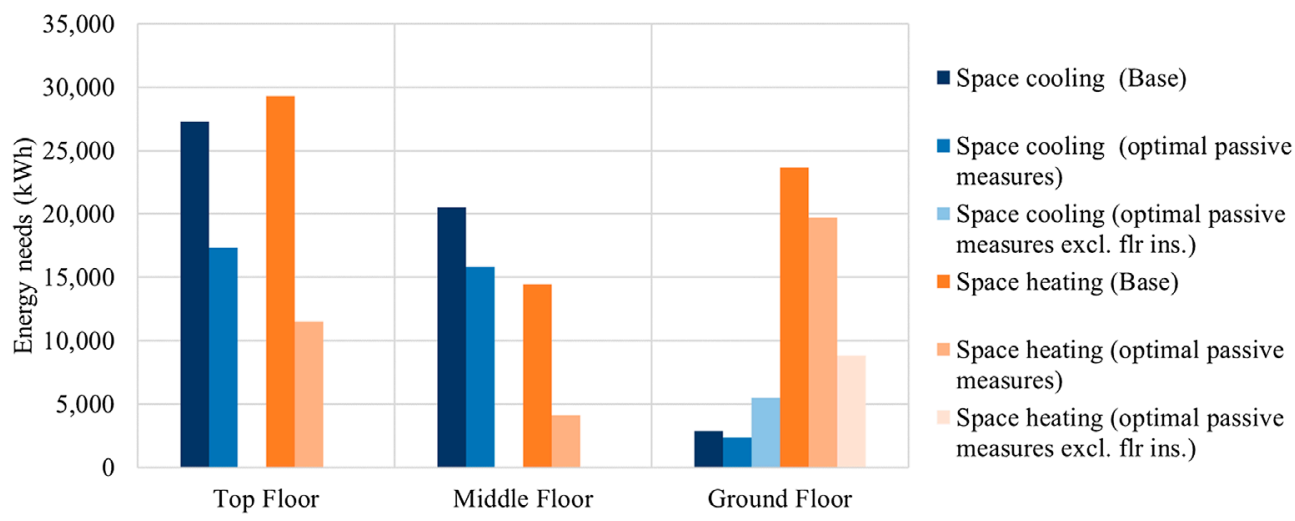

FIGURE 7 | Annual cooling and heating load energy needs (kWh) analysis for the base vs. the proposed passive measures scenarios grouped by floor level.

TABLE 3 | The first nearly zero energy buildings (NZEB) benchmark indicator.

Requirement 1: "Energy needs" benchmark indicator

Top floor apartment

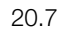

Space cooling needs $\left(\mathrm{kWh} \mathrm{m}^{-2} \mathrm{yr}^{-1}\right)$

Space heating needs ( $\mathrm{kWh} \mathrm{m}^{-2} \mathrm{yr}^{-1}$ )

Combined space heating and cooling needs $\left(\mathrm{kWh} \mathrm{m}^{-2} \mathrm{yr}^{-1}\right)$

20.7
13.7
34.4

Middle floor apartment

Ground floor apartment

Whole building

18.9
4.9
23.8

$\begin{array}{cc}2.8 & 15.32 \\ 23.6 & 9.96 \\ 26.4 & 25.3\end{array}$

15.32

9.96

25.3

A market research identified potential equipment retrofit measures for the NZEB second requirement. The measure with the highest energy savings potential is to replace the electric boilers for DHW with heat pumps, ${ }^{6}$ having an SCOP of 2.5. Space cooling and heating are minimal energy consumers compared to DHW and lighting, and the current trend is to install energy efficient equipment $(\mathrm{A}+)$ or better by default.

The next step checked the cost-optimality of replacing electric boilers with DHW heat pumps. The macroeconomic global LCC calculated to comply with EN 15459-1 (CEN, 2017) for DHW heat pumps over a 30 -year calculation period is $€ 207,595$ vs. $€ 336,549$ for the scenario with electric boilers. ${ }^{7}$ Thus, DHW heat pumps result to be cost-optimal.

${ }^{6}$ For the scope of this case study, heat pumps are considered as an energy efficient measure and not a RE. The only RE in this study is solar photovoltaics.

${ }^{7} \mathrm{DHW}$ heat pumps-capital cost $€ 52,427$ excl. VAT, annual maintenance cost is $2 \%$ of initial capital cost as per EN 15459-1:2017, DHW heat pumps lifetime: 15 years, electric boilers capital maintenance cost is $€ 0$ throughout calculation period, fuel electricity price: $€ 0.15$ per unit (5\% energy tax) without escalation, emissions: $0.000452 \mathrm{TCO}_{2}$ per kWh, carbon cost ranges from $€ 18$ per $\mathrm{TCO}_{2}$ in year 1 to $€ 55.80$ per $\mathrm{TCO}_{2}$ in year 30 , discount rate $3 \%$, LCC calculation period: 30 years.

\section{Third NZEB Requirement: "Non-Renewable Primary Energy Use Without Compensation Between Energy Carriers"}

For the third NZEB requirement, roof top solar PV were introduced to the BEM with optimal $\mathrm{COM}_{\mathrm{P}}$ and $\mathrm{COM}_{\mathrm{A}}$ inputs as to maximize the roof top area. For Malta to reach its RE targets, it is imperative that the PV potential is maximized. Thus, the PVs were inclined at five rather than the optimal $30^{\circ}$ angle for Malta, to fit more PV modules. In addition, limited spacing was allowed between any obstructions and PV modules, which is sufficient for maintenance work to be conducted but does not eliminate shading on the PV modules all year round. However, energy losses due to over shading has been minimized by proposing that PV modules are connected in parallel to separate inverters.

In total, a $68.6 \mathrm{~kW}_{\mathrm{p}}$ rooftop PV system is considered. The system was hourly simulated using EnergyPlus, which resulted in a

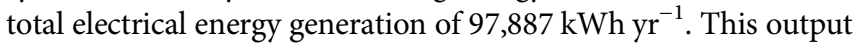
is equivalent to $1,419 \mathrm{kWh} \mathrm{kW}_{\mathrm{p}}^{-1} \mathrm{yr}^{-1}$. Given increased shading losses on the system being studied due to the limited spacing allowed between obstructions and $\mathrm{PV}$ modules, this resulting output is less than the $1,600-1,730 \mathrm{kWh} \mathrm{kW}_{\mathrm{p}}^{-1} \mathrm{yr}^{-1}$ (Stagno et al., 2011) generated by optimally designed PV systems in Malta.

The hourly PV generation from EnergyPlus and the hourly site energy use for the BEM with optimal $\mathrm{COM}_{\mathrm{A}}$ and $\mathrm{COM}_{\mathrm{P}}$ were inputted into the NREL System Advisor Model (NREL, 2011) 
software to explore different battery bank energy storage (BESS) combinations ${ }^{8}$ in terms of the three load matching and grid interaction indicators identified in ISO 52000-1:2017 (refer to section 2.2) and the macroeconomic global LCC. ${ }^{9}$ In total 66 bank capacities $(\mathrm{kWh})$ and power $(\mathrm{kW})$ combinations were analyzed ${ }^{10}$.

Figure 8 depict the load matching indicators [use matching fraction $\left(f_{\text {use }}\right)$, production matching fraction $\left.\left(f_{\mathrm{pr}}\right)\right]$ and the grid matching indicator [re-use production matching fraction $\left(f_{\text {reuse }}\right)$ ] plotted separately against battery capacity (kWh). In addition, Figure 9 plots the macroeconomic LCC $(€)$ against the battery capacity $(\mathrm{kWh})$.

As described in Method section, the "optimal" BESS combination $\left(\mathrm{COM}_{\mathrm{RE}+\text { storage }}\right)$, can be chosen either based on the lowest LCC or optimized to prioritize load matching and grid interaction. From Figure 9, the option resulting in the lowest LCC is the solution with no BESS giving $f_{\text {use }}=18.1, f_{\mathrm{pr}}=27$ and $f_{\text {reuse }}=73$ followed by a BESS combination having a capacity of $60 \mathrm{kWh}$ and power of $20 \mathrm{~kW}$ giving $f_{\mathrm{use}}=22.9, f_{\mathrm{pr}}=34.2$ and $f_{\text {reuse }}=60$. In contrast, a solution that prioritizes RE load matching is a BESS combination of $210 \mathrm{kWh}$ and a power of $30 \mathrm{~kW}$ giving $f_{\text {use }}=37.8, f_{\mathrm{pr}}=56.4$ and $f_{\text {reuse }}=40.8$. This point is found at the elbow of the load matching indicator curves. This BESS combination is "optimum" because it is up to this point that one experiences the maximum improvement in load matching indicators over a change in battery capacity or LCC.

Following this analysis, Table 5 depicts the resulting third NZEB benchmark indicator considering the two different BESS optimisations discussed. For this indicator, the PV export to the grid is not considered in the energy balance as per ISO 52000-1: 2017 definitions.

\section{Fourth NZEB Requirement: "Non-Renewable Primary Energy Use With Compensation Between Energy Carriers"}

The fourth NZEB benchmark considers the roof PV system, the PV energy used directly, and the PV energy exported energy $\left(71,420 \mathrm{kWh} \mathrm{yr}^{-1}\right)$ in the energy balance for the

\footnotetext{
${ }^{8}$ The system advisor model dispatch model was used in which stored energy from the battery is utilized to minimize power consumption from the grid. Battery charging from the grid is disabled. The selected mode is the Peakshaving 1-day look ahead to obtain the best scenario for the considered battery banks.

${ }^{9} \mathrm{PV}$ capital cost: $€ 1,362 \mathrm{kWh} \mathrm{kWp}{ }^{-1}$ excl. VAT, BESS system capital cost (ranged from $€ 41,699$ for $60 \mathrm{kWh}$ (20 kW system to $€ 256,708$ excl. VAT for the $510 \mathrm{kWh}$ $(50 \mathrm{~kW})$ system, PV and BESS system maintenance cost taken as $1 \%$ of capital cost throughout calculation period, fuel-electricity price: $€ 0.15$ per unit $(5 \%$ energy tax) without escalation, carbon emissions: $0.000452 \mathrm{TCO}_{2}$ per $\mathrm{kWh}$, carbon cost ranges from $€ 18$ per $\mathrm{TCO}_{2}$ in year 1 to from $€ 55.80$ per $\mathrm{TCO}_{2}$ in year 30 , Discount Rate 3\%, PV lifetime: 20 years, BESS lifetime: 15 years, annual system degradation rate: $0 \%$, replacement costs of systems considered the same as initial capital costs, LCC calculation period: 30 years.

${ }^{10}$ BESS storage capacities (kWh) of $105,110,115,120,125,130,135,150,210$ $270,330,390,450,510$ were analyzed for each of the following power ratings $(\mathrm{kW}): 20,30,40$ and 50 . BESS storage capacities $(\mathrm{kWh})$ of 80 and 90 were analyzed for each of the following power ratings (kW): 20, 30 and 40. BESS storage capacities $(\mathrm{kWh})$ of 60 and 70 were analyzed for the 20 and $30 \mathrm{~kW}$ power ratings.
} 


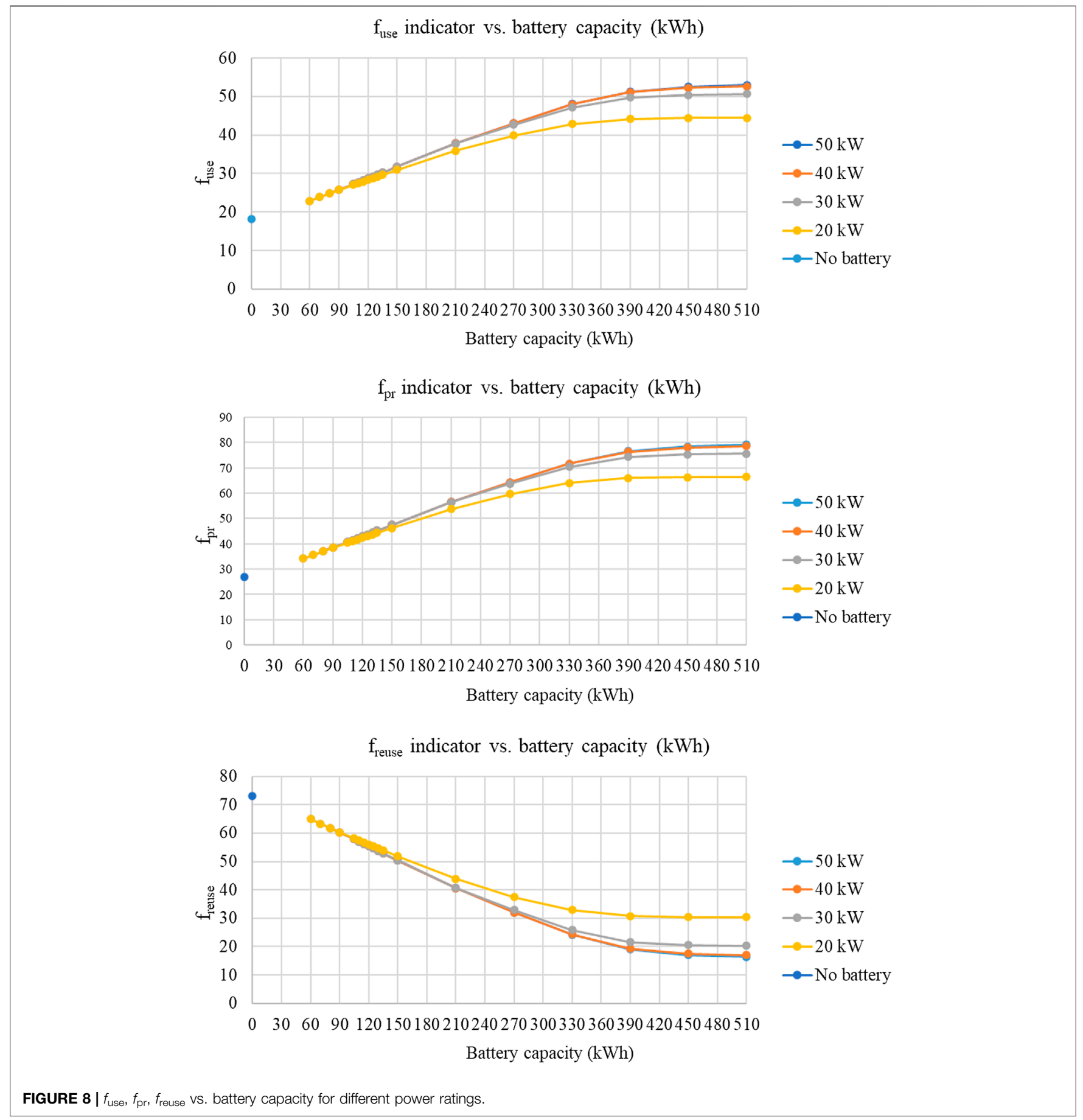

BEM with optimal $\mathrm{COM}_{\mathrm{P}}$ and $\mathrm{COM}_{\mathrm{A}}$ and no BESS ${ }^{11}$. The resulting benchmark is $28 \mathrm{kWh} \mathrm{m}^{-2} \mathrm{yr}^{-1}$ vs. 64 and $52 \mathrm{kWh} \mathrm{m}^{-2} \mathrm{yr}^{-1}$ depending on the BESS scenario for the third benchmark.

${ }^{11}$ Energy storage losses were not considered in the fourth NZEB benchmark indicator analysis.

\section{DISCUSSION}

This paper proposed an approach to derive NZEB benchmarks indicators for social housing buildings in line with the ISO 52000 1:2017 multiple NZEB indicators and aimed to meet the 2018 EPBD objectives for improving thermal comfort, tackling energy poverty while implementing BESS technologies to improve load matching and grid interaction which are vital for island states to enhance energy security. 
Global macroeconomic LCC $(€)$ vs. Battery capacity $(\mathrm{kWh})$

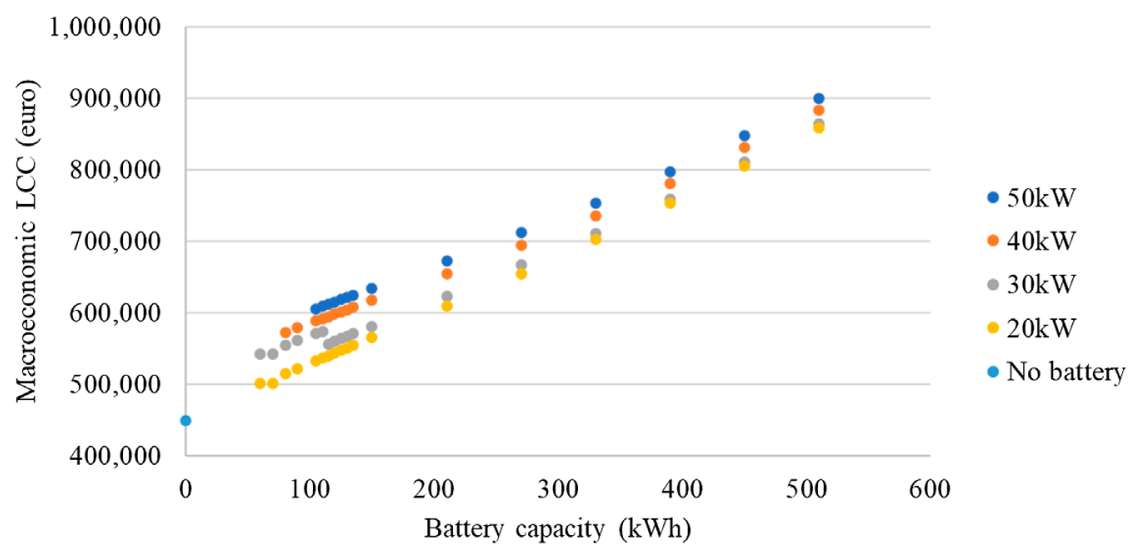

FIGURE 9 | Macroeconomic life cycle cost vs. battery capacity ( $\mathrm{kWh}$ ) for different power ratings.

To support the discussion, Table 6 provides an overview how the load matching/grid interaction factors together with the third and fourth NZEB benchmark are impacted both by different BESS and BEM energy efficiency configurations. The BESS configurations considered is the case with no battery storage, the lowest LCC optimal BESS, and the optimal load matching BESS derived in Third NZEB Requirement: "Non-Renewable Primary Energy Use Without Compensation Between Energy Carriers". For the BEM, the scenarios considered are 1) the base BEM with no retrofit measures, 2) the BEM with optimal $\mathrm{COM}_{\mathrm{P}}$ and base $\mathrm{COM}_{\mathrm{A}}$ i.e., with only the optimal passive measures implemented, 3) the BEM with base $\mathrm{COM}_{\mathrm{P}}$ and optimal $\mathrm{COM}_{\mathrm{A}}$ i.e., with only the optimal active measures implemented and 4) the BEM scenario with both passive and active measures implemented.

From Table 6, active measures and increasing the BESS capacity have a much larger impact on the indicators than retrofit passive measures given Malta's temperate climate. However, the proposed passive measures for such a housing stock have the potential to improve the wellbeing of occupants by allowing "free-running building" to become predominantly comfortable even when considering the hottest and coolest design weeks throughout the year as has been statistically proven in this study. Thus, although the proposed passive measures in this study go well beyond the Minimum EP Requirements for Buildings-Technical document F $(\mathrm{BRO}, 2015)$ and are therefore not cost-optimal, the optimization approach used in this study has an important role to play in a social housing stock, because it prioritizes the passive measures to reduce thermal discomfort. Social housing tenants are usually vulnerable and may not afford paying energy bills for mechanical space heating and cooling. Therefore, such an optimization approach is the only way to ensure that thermal comfort is optimized, and energy poverty is mitigated.

In addition, the requirement to optimize comfort as one of multiple NZEB benchmark indicators in building EP legislation is now fulfilled. Furthermore, the floor-by-floor energy analysis approach provided a more realistic solution, because from the surveys it was already noted that the level of indoor comfort was different for different floors (refer to Table 3).
Although the passive measures have a minimal impact on the indicators as reflected in Table 6, the cumulative expected reduction in peak heating and cooling demand for an entire building stock can have a significant benefit on the energy security requirements in small island states.

It can also be noted, that for temperate climates like Malta, where the application of passive measures has minimal impact on NZEB indicators but are critical for comfort and to minimize peak loads, the use of the current EPBD cost-optimal method that does not use a stepped approach but combines passive, active and RES measures together for the analysis should be made with caution. A one step approach further risks under-estimating the benefits of passive measures.

With respect to improving the third NZEB indicator, both retrofit active measures and BESS are important. However, DHW is cost-optimal, as is depicted in Third NZEB Requirement: "Non-Renewable Primary Energy Use Without Compensation Between Energy Carriers", while the BESS is not. This is true even from a macroeconomic approach that does not consider PV incentives and energy being exported at marginal cost. This results given the low cost of electricity in Malta (TVM, 2020) and the current high cost of the BESS. Thus, if one optimizes the BESS using a cost-optimality rather than optimizing load matching and grid interaction, there will be no or minimal difference between the resulting third and fourth NZEB indicator benchmarks, leading to minimal improvement in grid stability and energy security for island states. From a policy point of view, fiscal incentives for PV and BESS systems should eliminate feed-in-tariffs for building stocks with low energy cost per $\mathrm{kWh}$, as this may incentivize electricity export rather than bridging the gap between optimizing load matching and optimizing cost-optimality of the BESS.

It is proposed that future updates to the cost-optimal methodology should consider ways of accounting for nonenergy benefits including comfort, energy poverty and load matching in the macro-economic calculation, to provide more holistic and credible indicators. This will support the holistic approach of optimizing comfort, increasing efficiency and 
TABLE 5 | Derivation of the third nearly zero energy buildings (NZEB) benchmark indicator using different "optimization" criteria.

Primary energy

Electrical annual site energy (kWh)

\begin{tabular}{|c|c|c|c|c|}
\hline Total energy use & $\begin{array}{c}\text { PV energy generation } \\
\text { used directly via } \\
\text { grid }\end{array}$ & $\begin{array}{c}\text { PV energy generation } \\
\text { used directly via } \\
\text { storage }\end{array}$ & $\begin{array}{c}\text { Annual "Non-renewable primary } \\
\text { energy use" (kWh) }\end{array}$ & $\begin{array}{l}\text { Third NZEB benchmark } \\
\left(\mathrm{kWh} \mathrm{m}^{-2} \mathrm{yr}^{-1}\right)\end{array}$ \\
\hline 146,223 & 26,457 & 7,026 & 281,850 & 64 \\
\hline 146,223 & 26,457 & 28,722 & 227,609 & 52 \\
\hline
\end{tabular}

TABLE 6 | Whole building load matching, grid interaction and nearly zero energy buildings (NZEB) indicators under different passive, active and BESS scenarios.

\begin{tabular}{|c|c|c|c|c|c|}
\hline \multirow{2}{*}{$\begin{array}{l}\text { Roof top PV BESS } \\
\text { scenario }\end{array}$} & \multicolumn{5}{|c|}{ Building (BEM) passive and active measures scenario } \\
\hline & Whole building indicators & $\begin{array}{l}\text { Base } \operatorname{coM}_{\mathrm{P}} \text { and base } \\
\operatorname{com}_{\mathrm{A}}\end{array}$ & $\begin{array}{l}\text { Optimal } \operatorname{COM}_{\mathrm{P}} \text { and base } \\
\qquad \operatorname{COM}_{\mathrm{A}}\end{array}$ & $\begin{array}{l}\text { Base } \operatorname{COM}_{P} \text { and optimal } \\
\operatorname{COM}_{A}\end{array}$ & $\begin{array}{c}\text { Optimal } \operatorname{COM}_{\mathrm{p}} \text { and optimal } \\
\text { COMA }\end{array}$ \\
\hline \multirow[t]{5}{*}{ No BESS } & $f_{\text {use }}$ & 11.20 & 11.80 & 16.50 & 18.10 \\
\hline & $f_{\mathrm{pr}}$ & 31.60 & 31.00 & 27.70 & 27.00 \\
\hline & $f_{\text {reuse }}$ & 68.40 & 69.00 & 72.30 & 73.00 \\
\hline & Third NZEB requirement $\left(\mathrm{kWh} \mathrm{m}^{-2} \mathrm{yr}^{-1}\right)$ & 139.31 & 129.63 & 78.63 & 68.44 \\
\hline & Fourth NZEB requirement $\left(\mathrm{kWh} \mathrm{m}^{-2} \mathrm{yr}^{-1}\right)$ & 101.03 & 91.01 & 38.20 & 27.63 \\
\hline \multirow[t]{5}{*}{60 kWh 20 kW (lowest LCC BESS) } & $f_{\text {use }}$ & 13.50 & 14.40 & 20.40 & 22.90 \\
\hline & $f_{\mathrm{pr}}$ & 37.90 & 37.80 & 34.40 & 34.20 \\
\hline & $f_{\text {reuse }}$ & 61.30 & 61.40 & 64.80 & 60.00 \\
\hline & Third NZEB requirement $\left(\mathrm{kWh} \mathrm{m}^{-2} \mathrm{yr}^{-1}\right)$ & 135.75 & 125.83 & 74.91 & 64.42 \\
\hline & Fourth NZEB requirement $\left(\mathrm{kWh} \mathrm{m}^{-2} \mathrm{yr}^{-1}\right)$ & 101.03 & 91.01 & 38.20 & 27.63 \\
\hline \multirow[t]{5}{*}{210 kWh 20 kW (optimal load matching BESS) } & $f_{\text {use }}$ & 19.70 & 21.00 & 33.10 & 37.80 \\
\hline & $f_{\mathrm{pr}}$ & 55.30 & 55.10 & 55.10 & 56.40 \\
\hline & $f_{\text {reuse }}$ & 42.30 & 42.50 & 41.50 & 40.80 \\
\hline & Third NZEB requirement $\left(\mathrm{kWh} \mathrm{m}^{-2} \mathrm{yr}^{-1}\right)$ & 126.04 & 116.15 & 62.95 & 52.02 \\
\hline & Fourth NZEB requirement $\left(\mathrm{kWh} \mathrm{m}^{-2} \mathrm{yr}^{-1}\right)$ & 101.03 & 91.01 & 38.20 & 27.63 \\
\hline
\end{tabular}


generating $\mathrm{RE}$, in addition to the consideration of carbon emission costs described in the EPBD guidelines (European Parliament, 2012b).

The multi-indicator approach is also crucial to policy making. From a practical point of view, one can show a case where introducing BIPVs in the base scenario building would generate a further PV electricity output of approximately $56,000 \mathrm{kWh}$ per annum, which is sufficient to compensate for existing inefficiencies of the building envelope and building energy systems and therefore achieve an NZEB status with a single indicator. But this would defeat the whole philosophy behind the new EPBD and would jeopardize the EU's final aim of achieving carbon neutrality by 2050 .

Despite such positive impacts of the multi-indicator approach in achieving a more balanced NZEB energy profile that meets all the requirements of the new EPBD as demonstrated in this paper, such method can be challenging and more time consuming for policy makers during policy enforcement stage to ensure that buildings meet more than one NZEB benchmark. Furthermore, each benchmark in the multi-indicator approach must be defined with care as to ensure the correct balance between the application of passive, active, renewables and energy storage solutions when retrofitting a building to NZEB.

\section{CONCLUSION}

The current established EPBD cost-optimal methodologies using a one-step and one NZEB benchmark definition approach does not consider peak loads, building-grid interaction requirements and energy storage and therefore fails to fully address the challenges experienced by island states such as Malta in terms of energy supply security and independence. To counteract these inadequacies and support the new EPBD requirements in terms of addressing "smart-readiness," while optimizing comfort and tackling energy poverty, this research detailed and proposed an innovative multi-criteria approach adapted from ISO 52000-1: 2017. This is carried out by first optimizing adaptive comfort in "free-running mode" for deriving the first "energy needs" NZEB benchmark, before switching to mechanical space heating and cooling. When applying the proposed approach with the aid of EnergyPlus software, on a case study of an existing 40-family social housing block undergoing deep renovation, it was found that the application of an optimal combination of passive measures drastically reduces the EN 15251 adaptive discomfort hours for the block, while the peak demand for the remaining discomfort hours requiring mechanical heating and cooling are halved. Policy makers should therefore consider indicators for social housing buildings that go beyond cost-optimality and prioritize adaptive comfort to fully meet the EPBD requirements. Despite such positive impact of passive measures, the research has quantitatively demonstrated that quite often these passive measures are not cost-optimal, when referring to "total primary energy use" and "non-renewable primary energy use" NZEB indicators and costs. The main reason for this is Malta's temperate climate, which makes these passive measures less effective in lowering the energy rating of the building, when compared to that achieved with active and RE measures. Thus, the proposed multi-tier benchmarking approach ensures that each energy efficiency and RE measure is appropriately weighted on its own merits, rather than lumping all measures under a single benchmark indicator and always choosing cheap RE solutions before optimizing comfort and lowering peak loads. With regards to smartness indicators for load matching and grid interaction, a detailed analysis using system advisor model software demonstrated that BESS could match the RE supply to the demand, although this approach is still far away from being cost-optimal. The paper concluded that RE incentives should thus move away from feed-in tariffs and subsidize direct energy use, storage, and load matching given their high costs. Furthermore, the implemented macroeconomic cost-optimal analysis should also quantify the costs of thermal discomfort, energy poverty and grid mismatch in the cost-optimal analysis to ensure a level playing field for passive, active and RE measures, which would best fit the deep renovation of buildings. Future research should therefore focus on applying the multi-criteria approach demonstrated in this research that considers a more comprehensive macroeconomic analysis.

\section{DATA AVAILABILITY STATEMENT}

Raw data will only be made available once approval from all relevant stakeholders including the housing authority is sought by the authors.

\section{AUTHOR CONTRIBUTIONS}

DG: Conceptualization, methodology, software, validation, investigation, formal analysis, writing-original draft, writing-review and editing. CC: Methodology, software, validation, investigation, writing-original draft, writing-review and editing. CY: Methodology, supervision, resources, investigation, data curation, validation, writing-original draft, writing-review and editing.

\section{FUNDING}

University of Malta supports research in the area of energy performance of buildings.

\section{ACKNOWLEDGMENTS}

The authors wish to thank the Housing Authority in Malta for providing data and access to the Housing Block case study and for their full support and cooperation throughout this study. 


\section{REFERENCES}

Addinsoft XLSTAT (2020). Available at: https://www.xlstat.com/en/ (Accessed May 7, 2020).

ALDREN Project (2017). ALDREN alliance for Deep RENovation in buildings. Available at: https://aldren.eu/ (Accessed August 11, 2020).

Anita, D., Zoritsa, U., Claudia, L., Sandra, de. P., Tournaki, S., and Tsoutsos, T. (2016). Nearly Zero Energy Hotels (neZEH) towards low carbon growth in the European Union Nezeh position paper. Available at: http://www.nezeh.eu/ assets/media/PDF/neZEH_EU_position_paper248.pdf.

ANSI/ASHRAE (2014). ASHRAE guideline 14-2014 measurement of energy and demand savings. Atlanta, GA: Ashrae, 140.

Attia, S. (2018). "Evolution of definitions and approaches," in Net zero energy buildings (NZEB) concepts, frameworks and roadmap for project analysis and implementation. Canada: Elsevier Inc., 21-51.

Bean, F., Volt, J., and Dorizas, V. (2018). Future-proof buildings for all Europeans-a guide to implement the energy performance of buildings directive. Buildings Performance Institute Europe (Brussels, Belgium). Available at: http://bpie.eu/ wp-content/uploads/2019/04/Implementing-the-EPBD_BPIE_2019.pdf. doi:10. 4324/9781315173382

Berardi, U. (2018). "ZEB and NZEB (definitions, design methodologies, good practices, and case studies)," in Handbook of energy efficiency in buildings. Editors U. Desideri and F. Asdrubali (London, UK: Butterworth-Heinemann), 75-205. doi:10.1016/b978-0-12-812817-6.00038-3.

Boermans, T., Bettgenhauser, K., Offerman, M., and Schimschar, S. (2012). Renovation tracks for Europe up to 2050. Available at: http://www.eurima. org/uploads/ModuleXtender/Publications/90/Renovation_tracks_for_Europe_ 08_06_2012_FINAL.pdf (Accessed 10 February, 2020).

Building Regulation Office (BRO) (2015). Technical document F Part 1. Available at: https://epc.gov.mt/legislation.

Buildings Performance Institute Europe (BPIE) (2011). Principles for nearly zero-energy buildings, paving the way for effective implementation of policy requirements. Available at: http://bpie.eu/documents/BPIE/publications/LR_nZEB study.pdf (Accessed 11 February, 2020).

Buildings Performance Institute Europe (BPIE) (2013). A guide to developing strategies for building energy renovation, delivering article 4 of the energy efficiency directive. Available at: http://bpie.eu/publication/a-guide-todeveloping-strategies-for-building-energy-renovation/ (Accessed 10 April, 2020).

Candanedo, J. A., Salom, J., Widén, J., and Athienitis, A. (2015). "Load matching, grid interaction, and advanced control," in Modeling, design, and optimization of net zero-energy buildings. Editors A. Athienitis and W. O'Brien (Berlin, Germany: Ernst \& Sohn-A Wiley Brand), 207-240.

CEN (2007). Standard EN 15251 - 2007 : indoor environmental input parameters for design and assessment of energy performance of buildings addressing indoor air quality, thermal environment, lighting and acoustics. Brussels, Belgium: Comité Européen de Normalisation (CEN), 3.Google Scholar

CEN (2017). EN 15459-1:2017 energy performance of buildings-economic evaluation procedure for energy systems in buildings-Part 1: calculation procedures, Module M1-14. Brussels, Belgium: Comité Européen de Normalisation (CEN).

CEN (2019). EN 16798-1 energy performance of buildings-ventilation for buildings-Part 1: indoor environmental input parameters for design and assessment of energy performance of buildings addressing indoor air quality, thermal environment, lighting and acoustics. Brussels, Belgium: Comité Européen de Normalisation (CEN).

Chesire, D., and Grant, Z. (2007). Sustainability CIBSE guide L. Editor K. Butcher (Norwich, UK: Chartered Institution of Building Services).

Clean Energy for EU Islands Secretariat (2018). Welcome to the clean energy for EU islands Secretariat! Available at: https://euislands.eu/ (Accessed May 10, 2020).

CommONEnergy (2013). CommONEnergy project Re-conceptualize shopping malls from consumerism to energy conservation. CommONEnergy under FP7 EU Program. Available at: http://commonenergyproject.eu/objectives.html (Accessed May 7, 2020).

Crawley, D. B., Lawrie, L. K., Winkelmann, F. C., Buhl, W. F., Huang, Y. J., Pedersen, C. O., et al. (2001). EnergyPlus: creating a new-generation building energy simulation program. Energy Build. 33, 319-331. doi:10.1016/S0378 7788(00)00114-6

D'Agostino, D. (2015). Assessment of the progress towards the establishment of definitions of nearly zero energy buildings (nZEBs) in European member states. J. Build. Eng. 1, 20-32. doi:10.1016/j.jobe.2015.01.002

Department for Communities and Local Government (2008). Definition of zero carbon homes and non-domestic buildings consultation. Available at: http:// www.zerocarbonhub.org/sites/default/files/resources/reports/Definition_of_ Zero_Carbon_Homes_and_Non-Domestic_Buildings.pdf (Accessed $01 \mathrm{March}$, 2020)

Department for Communities and Local Government (2015). Improving the energy efficiency of our buildings - a guide to display energy certificates and advisory reports for public buildings. Available at: https://assets.publishing. service.gov.uk/government/uploads/system/uploads/attachment_data/file/ 452481/DEC_Guidance rev_July_2015_pdf (Accessed 05 May, 2020).

DesignBuilder. Available at: http://www.designbuilder.co.uk/ (Accessed May 7, 2020).

Enemalta (2020). Interconnector repairs completed. Available at: https://www. enemalta.com.mt/home-page-news/interconnecot-repairs-completed/ (Accessed May 10, 2020)

Ernst \& Young (2010). Business opportunities in a low carbon economy, final report. Industry and Investment NSW. Available at: https://www.industry.nsw. gov.au/_data/assets/pdf_file/0011/55379/E-and-Y-Low-Carbon-EconomyReport_Final.pdf.

EU (2010). Directive 2010/31/EU of the European Parliament and of the Council of 19 May 2010 on the energy performance of buildings (recast). Off. J. Eur. Union (Brussels, Belgium), 13-33. Available at: https://eur-lex.europa.eu/legalcontent/EN/TXT/PDF/?uri=CELEX:32010L0031\&from=EN (Accessed 08 May, 2020).

EU (2018). Directive (EU) 2018/844 of the European parliament and of the council of 30 May 2018 Amending Directive 2010/31/EU on the energy performance of buildings and Directive 2012/27/EU on energy efficiency. Off. J. Eur. Union (Brussels, Belgium), 75-91.

European Commission (2011). COM(2011) 112 final: Communication from the commission to the european parliament, the council, the european economic And social committee and the committee of the regions: a roadmap for moving to a competitive low carbon economy in 2050. Available at: https://ec.europa. eu/energy/sites/ener/files/documents/2012_energy_roadmap_2050_en_0.pdf (Accessed 05 April, 2020).

European Commission (2012). Commission Regulation (EU) No 206/2012 of 6 March 2012 implementing Directive 2009/125/EC of the European Parliament and of the Council with regard to ecodesign requirements for air conditioners and comfort fans. Off. J. Eur. Union L, 7-27.

European Commission (2016). Commission Recommendation (EU) 2016/1318 of 29 July 2016 on guidelines for the promotion of nearly zero-energy buildings and best practices to ensure that, by 2020 , all new buildings are nearly zeroenergy buildings. Available at: https://eur-lex.europa.eu/legal-content/EN/ TXT/PDF/?uri=CELEX:32016H1318\&from=RO (Accessed 20 March, 2020).

European Parliament (2012a). Directive 2012/27/EU of the European Parliament and of the Council of 25 October 2012 on energy efficiency, amending Directives 2009/125/EC and 2010/30/EU and repealing Directives 2004/8/EC and 2006/32/ EC text with EEA relevance. Off. J. Eur. Union, (Brussels, Belgium).

European Parliament (2012b). Guidelines accompanying commission delegated regulation (EU) No 244/2012 of 16 January 2012 (European Parliament: Brussels, Belgium)

Fabbri, M., De Groote, M., and Rapf, O. (2016). Building renovation passports customised roadmaps towards deep renovations and better homes. Building Performance Institute Europe (Brussels, Belgium). Available at: http://bpie.eu/ wp-content/uploads/2017/01/Building-Passport-Report_2nd-edition.pdf (Accessed August 11, 2020).

Gatt, D., and Yousif, C. (2016a). "Intelligent retrofitting of a primary school building in Malta," in Proceedings of intelligent buildings: the 24th annual engineering conference, Golden Bay, Malta. (Malta: Chamber of Engineers), published in Engineering Today, August 2016, Issue 54, 18-27. Available at: https://www.um.edu.mt/library/oar/bitstream/handle/123456789/26131/COE siggiewi paper.pdf? sequence $=3$ \&isAllowed $=y$.

Gatt, D., and Yousif, C. (2016b). "ZeroCO 2 building-how low can we go: a case study of a small hotel in Gozo-Malta," in Proceedings of the sustainable energy 
2016: the ISE annual conference, Valletta, Malta. October 2016. (St Paul's Bay, Malta: Institute for Sustainable Energy, University of Malta), 30-37. Available at: https://www.um.edu.mt/library/oar/handle/123456789/23284 (Accessed 21 March, 2020).

Gatt, D., Yousif, C., Cellura, M., Camilleri, L., and Guarino, F. (2020). Assessment of building energy modelling studies to meet the requirements of the new energy performance of buildings directive. Renew. Sustain. Energy Rev. 127, 109886. doi:10.1016/j.rser.2020.109886.

Grondzik, W. T., Kwok, A. G., Stein, B., and Reynolds, J. S. (2010). Mechanical and electrical equipment for buildings. Hoboken, NJ: John Wiley \& Sons.

Hamdy, M., Hasan, A., and Siren, K. (2013). A multi-stage optimization method for cost-optimal and nearly-zero-energy building solutions in line with the EPBD-recast 2010. Energy Build. 56, 189-203. doi:10.1016/j.enbuild.2012.08. 023 .

НОВО НОВО UX100-003 temperature/relative humidity data logger. Available at: https://www.onsetcomp.com/products/data-loggers/ux100-003/ (Accessed May 7, 2020).

IBRoad Project (2017). iBRoad individual building renovation roadmaps. Available at: https://ibroad-project.eu/ (Accessed August 11, 2020).

Intelligent Energy Europe (2014). RePublic_Zeb Project ZEROING IN ON ENERGY. Available at: http://www.republiczeb.org/ (Accessed May 7, 2020).

International Energy Agency (2015a). IEA SHC Task 40. Available at: http:// task40.iea-shc.org/ (Accessed May 7, 2020).

International Energy Agency (2015b). Net zero energy solar buildings. Available at: http://task40.iea-shc.org/ (Accessed 15 March, 2020).

Interreg Europe (2016). ZeroCO $\mathrm{CO}_{2}$-promotion of near zero $\mathrm{CO}_{2}$ emission buildings due to energy use. Available at: http://www.interregeurope.eu/zeroco2/ (Accessed May 10, 2020).

ISO (2017a). ISO 52000-1:2017 energy performance of buildings-overarching EPB assessment-Part 1: general framework and procedures. ISO, 2017.

ISO (2017b). ISO 6946:2017 building components and building elements-thermal resistance and thermal transmittance-calculation methods. ISO, 2017.

Kurnitski, J., Allard, F., Braham, D., Goeders, G., Heiselberg, P., Jagemar, L., et al. (2012). How to define nearly net zero energy buildings nZEB-REHVA proposal for uniformed national implementation of EPBD recast. REHVA Eur. HVAC J. 48, 6-12.

Laustsen, J. (2008). Energy efficiency requirements in building codes, energy efficiency policies for new buildings. Paris, France: OECD (Organisation for Economic Co-Operation and Development). doi:10.1.1.378.1012.

Loeppky, J. L., Sacks, J., and Welch, W. J. (2009). Choosing the sample size of a computer experiment: a practical guide. Technometrics 51, 366-376. doi:10. 1198/TECH.2009.08040.

Ma, Z., Cooper, P., Daly, D., and Ledo, L. (2012). Existing building retrofits: methodology and state-of-the-art. Energy Build. 55, 889-902. doi:10.1016/j. enbuild.2012.08.018.

Malta EU Presidency (2017). Valletta 18 may 2017 political declaration on clean energy for EU islands. Available at: https://ec.europa.eu/energy/sites/ener/files/ documents/170505_political_declaration_on_clean_energy_for_eu_islandsfinal_version_16_05_20171.pdf (Accessed 18 April, 2020).

Marszal, A. J., Bourrelle, J. S., Musall, E., Heiselberg, P., Gustavsen, A., and Voss, K. (2010). "Net zero energy buildings-calculation methodologies versus national building codes," in EuroSun Conf., 2, May 2010.

Marszal, A. J., Heiselberg, P., Bourrelle, J. S., Musall, E., Voss, K., Sartori, I., et al. (2011). Zero energy building-a review of definitions and calculation methodologies. Energy Build. 43, 971-979. doi:10.1016/j.enbuild.2010.12.022.

Marszal, J., and Heiselberg, P. (2012). Zero energy building definition-a literature review A technical report of subtask A. Task40/Annex52, 1-16.

Menassa, C. C., and Ortiz-Vega, W. (2013). "Uncertainty in the refurbishment investment," in Nearly zero energy building refurbishment: a multidisciplinary approach. London, UK: Springer-Verlag, 143-175.

Menberg, K., Heo, Y., and Choudhary, R. (2016). Sensitivity analysis methods for building energy models: comparing computational costs and extractable information. Energy Build. 133, 433-445. doi:10.1016/j.enbuild.2016.10.005.

Mitra, I. (2009). Optimum utilization of renewable energy for electrification of small islands in developing countries. Kassel, Germany: Kassel University Press.

National Statistics Office (NSO) (2019). Renewable energy from photovoltaic panels (PVs): 2018. Available at: https://nso.gov.mt/en/News_Releases/View_by_Unit/
Unit_02/Regional_and_Geospatial_Statistics/Documents/2019/News2019_097. pdf (Accessed 09 May, 2020).

Nguyen, A.-T., and Reiter, S. (2015). A performance comparison of sensitivity analysis methods for building energy models. Build. Simul. 8, 651-664. doi:10. 1007/s12273-015-0245-4

NREL (2011). System advisor model (SAM). National Renewable Energy Laboratory (Golden, Colorado, U.S.A.).

O’Brien, W., Bourdoukan, P., Delisle, V., and Yip, S. (2015). "Net ZEB design processes and tools," in Modeling, design, and optimization of net zero-energy buildings. Editors A. Athienitis and W. O'Brien (Ernst \& Sohn-A Wiley Brand), 107-173 (Accessed 13 April, 2020).

Office of the Prime Minister (Energy and Projects) (2017). Malta's national energy efficiency action plan (NEEAP). Available at: https:/ec.europa.eu/energy/sites/ ener/files/documents/mt_neeap_2017.pdf (Accessed 13 March, 2020).

Parliament, E. (2012). Commission delegated regulation (EU) No 244/2012 of 16 January 2012 supplementing Directive 2010/31/EU of the European Parliament and of the Council on the energy performance of buildings by establishing a comparative methodology framework for calculating. EU Official Journal EURLex, (Brussels, Belgium).

Said, G. (2012). Development of detailed statistics on energy consumption in households. Available at: https://ec.europa.eu/eurostat/cros/system/files/ SECH_Project_Malta.pdf.

Saltelli, A., Tarantola, S., Campolongo, F., and Ratto, M. (2004). Sensitivity analysis in practice: a guide to assessing scientific models. England, UK: John Wiley and Sons. doi:10.1198/jasa.2006.s80

Sartori, I., Napolitano, A., and Voss, K. (2012). Net zero energy buildings: a consistent definition framework. Energy Build. 48, 220-232. doi:10.1016/j. enbuild.2012.01.032

SENSIBLE (2015). Storage-enabled sustainable energy for buildings and communities (2015-2018). H2020. Available at: https://cordis.europa.eu/ project/id/645963 (Accessed May 10, 2020).

Sesana, M. M., Rivallain, M., and Salvalai, G. (2020). Overview of the available knowledge for the data model definition of a building renovation passport for non-residential buildings: the ALDREN project experience. Sustainability 12, 642. doi:10.3390/su12020642

Sesana, M. M., and Salvalai, G. (2018). A review on building renovation passport: potentialities and barriers on current initiatives. Energy Build. 173, 195-205. doi:10.1016/j.enbuild.2018.05.027

Sobol', I. M. (1967). On the distribution of points in a cube and the approximate evaluation of integrals. USSR Comput. Math. Math. Phys. 7, 86-112. doi:10. 1016/0041-5553(67)90144-9

Stagno, M. L., Yousif, C., and Palacios, E. R. V. (2011). "Solar photovoltaic systems performance in Malta: potential versus real contribution to the 2020 RE target," in Proceedings of the 26th European photovoltaic solar energy conference, Hamburg, Germany, September 5-9, 2011, 4381-4384. Available at: https:// www.um.edu.mt/library/oar/handle/123456789/26121 (Accessed 09 May, 2020).

Sweatman, P., and Managan, K. (2010). Financing energy efficiency building retrofits. International policy and business model review and regulatory alternatives for Spain. Madrid, Spain: Climate Strategy and Partners.

The Energy and Water Agency (EWA) (2019). Malta's 2030 national energy and climate plan. Available at: https://drive.google.com/file/d/11nQdlwQghCXKjrKIG9V6xSIvOfDZz0q/view (Accessed February 3, 2020).

The Energy and Water Agency (EWA) (2017). The national renewable energy action plan (NREAP) 2015-2020. Available at: https://drive.google.com/file/d/ 18afxVA-V6YmrNrF0yus6Xv-rmHuTnLCM/view (Accessed May 10, 2020).

The MaTrID Project (2014). Integrated design process guide. Available at: http://www.integrateddesign.eu/downloads/MaTrID_Process-Guideline. pdf (Accessed 12 April, 2020).

Tian, W. (2013). A review of sensitivity analysis methods in building energy analysis. Renew. Sustain. Energy Rev. 20, 411-419. doi:10.1016/j.rser.2012.12.014

Torcellini, P., Pless, S., Deru, M., and Crawley, D. (2006). "Zero energy buildings: a critical look at the definition," in ACEEE Summer Study Pacific Grove, 15. doi:10.1016/S1471-0846(02)80045-2

Torgal, F. P., Mistretta, M., Kaklauskas, A., Granqvist, C. G., and Cabeza, L. F. (2014). Nearly zero energy building refurbishment: a multidisciplinary approach. London, UK: Springer-Verlag. doi:10.1007/978-1-4471-5523-2 
TVM (2020). Malta with third cheapest cost of electricity among European Union countries. Available at: https:/www.tvm.com.mt/en/news/maltawith-third-cheapest-cost-of-electricity-among-european-union-countries/. (Accessed May 10, 2020).

Tymkow, P., Tassou, S., Kolokotroni, M., and Jouhara, H. (2013). Building services design for energy efficient buildings. Routledge, UK: Taylor and Frances Group. doi:10.4324/9780203840733

Yang, S., Tian, W., Cubi, E., Meng, Q., Liu, Y., and Wei, L. (2016). Comparison of sensitivity analysis methods in building energy assessment. Procedia Eng. 146, 174-181. doi:10.1016/j.proeng.2016.06.369

\section{GLOSSARY}

ASHRAE American Society of Heating, Refrigerating and AirConditioning Engineers

BEM building energy model

BESS battery bank energy storage

BIPVs building integrated photovoltaics

BPIE buildings performance Institute Europe

BRO building regulation office (Malta)

CEN Comité Européen de Normalization

COM combination of measure

COMS combination of measures

DHW domestic hot water

EP energy performance

EPB energy performance of buildings

EPBD energy performance of buildings directive

EPC energy performance certificate

EPW EnergyPlus weather

EU European Union

EWA energy and water agency

IAQ indoor air quality

IEA International Energy Agency

ISO International Organization for Standardization

LCC life cycle cost

MS member states

PV photovoltaics

PVC polyvinyl chloride

NCM National Calculation Methodology

NEEAP National Energy Efficiency Action Plan

NECP National Energy and Climate Plan

NREAP National Renewable Energy Action Plan for Malta

NSO National Statistics Office (Malta)
NZEB nearly zero energy buildings

NZER nearly zero building energy refurbishment

RB reference building

RE renewable energy

SA sensitivity analysis

SAM system advisor model

SAP standard assessment procedure

SBEM simplified building energy model

SCOP (for heating) seasonal coefficient of performance

SEER (for cooling) seasonal energy efficiency ratio

SENSIBLE storage-enabled sustainable energy for buildings and communities

SHC-IEA solar heating and cooling program

SRC standardized regression coefficient

SRI smartness readiness indicator

ZEB or net ZEB net zero energy buildings

\section{SYMBOLS}

$f$ factor (e.g. primary energy factor, $\ldots$ )

$f_{\text {use }}$ use matching fraction

$f_{p r}$ production matching fraction

$f_{\text {reuse }}$ reuse production matching fraction

$\boldsymbol{U}$ thermal transmittance $\left(\mathrm{W} /\left(\mathrm{m}^{2} \mathrm{~K}\right)\right)$

$\mathbf{k}$ value kappa value

\section{SUBSCRIPTS}

A active measures

p peak

$\mathbf{P}$ passive measures

RE + storage renewable energy combined with energy storage

Conflict of Interest: The authors declare that the research was conducted in the absence of any commercial or financial relationships that could be construed as a potential conflict of interest.

Copyright (c) 2020 Gatt, Caruana and Yousif. This is an open-access article distributed under the terms of the Creative Commons Attribution License (CC BY). The use, distribution or reproduction in other forums is permitted, provided the original author(s) and the copyright owner(s) are credited and that the original publication in this journal is cited, in accordance with accepted academic practice. No use, distribution or reproduction is permitted which does not comply with these terms. 